\title{
烯烃的双官能团化反应研究进展
}

\author{
付晓飞 $a$ 赵文献 $*, a, b$ \\ $\left({ }^{a}\right.$ 郑州大学化学与分子工程学院 郑州 450000) \\ ( $b$ 商丘师范学院化学化工学院 商丘 476000)
}

\begin{abstract}
摘要 作为一类重要的有机化学反应, 烯烃的双官能团化反应不仅可以经济有效地一步合成多位点反应产物，而且可 以将起始原料转化为多种含有生物活性或药物活性的化合物, 同时还为构建化学结构的多样性提供了更多的方法, 所 以发展烯烃的双官能团化反应十分重要. 对近十二年来各类烯烃的双官能团化反应进行了综述. 主要分为: 铜催化的 烯烃的双官能团化反应、其它过渡金属催化的烯烃的双官能团化反应以及非金属催化的烯烃的双官能团化反应. 同时 对该类反应的发展前景进行了展望.
\end{abstract}

关键词＼cjkstart烯烃; 双官能团化; 催化

\section{Progress in Difunctionalization of Alkenes}

\author{
$\mathrm{Fu}, \mathrm{Xiaofei}^{a} \quad$ Zhao, Wenxian ${ }^{*, a, b}$ \\ $\left({ }^{a}\right.$ College of Chemistry and Molecular Engineering, Zhengzhou University, Zhengzhou 450000) \\ ( ${ }^{b}$ College of Chemistry and Chemical Engineering, Shangqiu Normal University, Shangqiu 476000)
}

\begin{abstract}
As an important kind of organic chemical reaction, difunctionalization of alkenes can not only synthesize multi-site reaction products effectively in one step, but also transform the starting material into other compounds that containing biological activity or drug activity. At the same time, it provides more methods for the construction of chemical structure diversity, so it is very important to develop the bifunctionalization of alkenes. In this paper, the bifunctionalization of various alkenes in recent 12 years is reviewed. It can be divided into three parts: copper-catalyzed difunctionalization of alkenes, other transition metal-catalyzed difunctionalization of alkenes, and non-metal-catalyzed difunctionalization of alkenes. The prospects of this reaction are also discussed.
\end{abstract}

Keywords alkene; bifunctionalization; catalysis

在有机合成领域, 追求 “Ideal Synthesis” 是一个经 久不衰的话题 ${ }^{[1]}$. 因此, 有机串联反应和多组分反应, 以其在单步操作中可实现高效的多个化学转化的特点, 引起了化学界的广泛关注. 随后, 大量与之相联系的方 法出现，而且还不断地被发现着，这些发现更充分发挥 了相关起始原料的多功能性, 其中烯烃的双官能团化反 应一直是个热门话题 ${ }^{[2]}$. 特别是在 $\mathrm{C}-\mathrm{H}$ 功能化领域快 速发展的推动下, 过渡金属催化的烯烃的双官能团化反 应在近几年取得了巨大的进展 ${ }^{[3]}$.

烯烃类化合物由于其便宜易得的特点，在有机合成 的发展中占有极为重要的地位. 二十世纪中期, Wacker

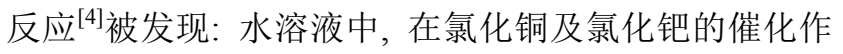

用下，用空气(氧气)直接把烯烃氧化成醛或酮. 这一反 应成功地应用到了工业生产中，同时也广泛地应用于有 机合成中, 此后, 对于烯烃的官能团化研究更加受到了 研究者们的重视. 烯烃是非常普遍的前手性基团, 化学 家常通过一步法使那些非手性的化合物转化为手性化 合物，且可以合成高度复杂的化合物，因此烯烃的双官 能团化反应非常重要.

烯烃的双官能团化反应作为一类重要的有机合成 反应，不仅可以经济有效地一步合成多位点反应产物， 而且可以将起始原料转化为多种含有生物活性或药物 活性的化合物. 近年来, 烯烃的双官能团化反应迅速发 展，主要报道了一些过渡金属如: $\mathrm{Rh} 、 \mathrm{Pd} 、 \mathrm{Fe} 、 \mathrm{Cu} 、 \mathrm{Ag}$ 、

\footnotetext{
* Corresponding author. E-mail: zhwx2595126@163.com

Received August 27, 2018; revised November 1, 2018; published online November 25, 2018.

Project supported by the National Natural Science Foundation of China (Nos. 20972091, 21172139) and the Key Science Research of Education Committee in Henan Province (No. 16A150020).

国家自然科学基金(Nos. 20972091, 21172139)、河南省高等学校重点科研(No. 16A150020)资助项目.
} 
$\mathrm{Au}$ 等催化的烯烃的双官能团化反应以及一些应用有机 小分子催化的反应. 由于非金属试剂毒性低、便宜易得、 一般符合绿色化学的要求, 因此发展非金属条件下发生 的双官能团化反应, 已成为此类反应的一个重要研究方 向.

\section{1 铜催化的烯烃的双官能团化反应}

\section{1 烯烃的氨基化反应}

\section{1 .1 烯烃的二氨化反应}

邻二胺作为一种非常重要的官能团, 广泛地存在于 生物活性化合物和天然产物中, 是医药制剂和农用化学 品中的关键结构元素, 同时也为手性配体、有机催化剂 和辅助剂的开发提供了极好的平台 ${ }^{[5]}$. 因此, 从现有前 体化合物快速合成邻二胺一直是有机合成中的一个重 要目标, 而人们也为开发高效的合成方法投入了很大的 努力. 鉴于邻二胺的重要用途, 烯烃的二氨化反应激发 了许多合成方法的发展.

2007 年, Shi 课题组 ${ }^{[6]}$ 报道了以 $\mathrm{CuCl}$ 作为催化剂, 二叔丁基二氮杂环丙酮为氮源的共轭烯烃的二氨化反 应, 具有很广的底物范围, 一些共轭三烯也可以以较好 的产率得到二氨化产物, 反应均在端烯位置进行, 且推 测该反应可能为自由基反应历程. 随后, 2008 年该课题 组 ${ }^{[7]}$ 又对此反应进行了不对称方面的研究, 笁选出 $(R)-$ DTBM-SEGPHOS 为手性配体, 但是只得到了中等的 $e e$ 值(Scheme 1).

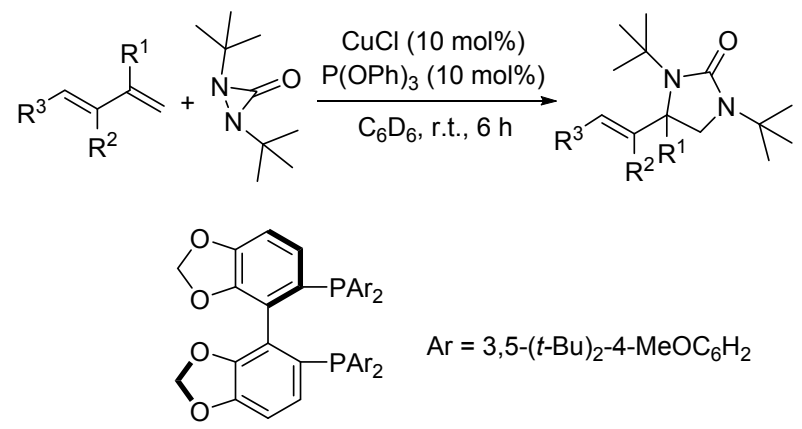

(R)-DTBM-SEGPHOS

图式 1 铜(I)催化共轭烯烃的二氨化反应

Scheme $1 \mathrm{Cu}(\mathrm{I})$-catalyzed diamination of conjugated dienes

2010 年, Shi 课题组 ${ }^{[8]}$ 又报道了铜催化的共轭烯烃 与二叔丁基二氮杂环丙酮区域选择性的二氨化反应. 与 之前不同的是, 这一反应以 $\mathrm{CuBr}$ 为催化剂, 发生在共 轭烯烃的非末端位置, 也可以得到较高产率的底物. 2011 年, Shi 课题组 ${ }^{[9]}$ 又深入研究了该反应的机理, 一价 铜催化剂与底物二烯上的取代基都对该反应的区域选 择性有高度的影响，且反应涉及自由基历程(Scheme 2).

2014 年, Shi 课题组 ${ }^{[10]}$ 再次报道了 $\mathrm{CuBr}$ 催化的端烯

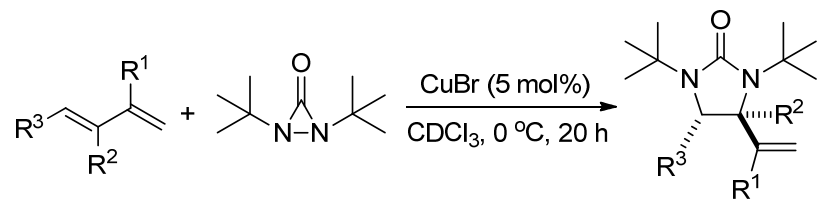

图式 2 铜(I)催化共轭烯烃的区域选择性二氨化反应 Scheme $2 \mathrm{Cu}(\mathrm{I})$-catalyzed regioselective diamination of conjugated dienes

与二叔丁基二氮杂环丙酮的二氨化反应, 生成咪唑啉2-酮, 这是生物活性分子中的一种重要结构, 且此反应 产物在此条件下会接着发生脱氢反应(Scheme 3).

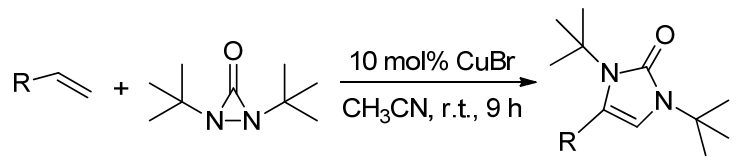

图式 3 铜催化末端烯烃连续的二氨化作用和脱氢作用 Scheme 3 Cu-catalyzed sequential diamination and dehydrogenation of terminal olefins

2010 年, Chemler 课题组 ${ }^{[11]}$ 首次报道了铜催化剂诱 导的烯烃分子内二氨化的不对称反应，它无论对于分子 内还是分子外的氨源都有很好的容忍性，可以生成各种 不同功能化的氮杂环化合物，产率高达 97\% (Scheme 4).

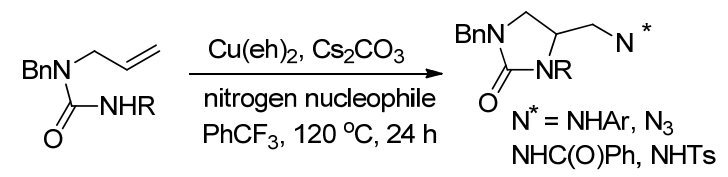

图式 4 铜催化烯烃的分子内二氨化反应

Scheme 4 Cu-catalyzed intermolecular alkene diamination

2012 年, Chiba 课题组 ${ }^{[12]}$ 报道了 $N$-烯丙基脒类化合 物以铜(I)作为催化剂, 增氧条件下发生 $[3+2]$ 成环反应 (Scheme 5).

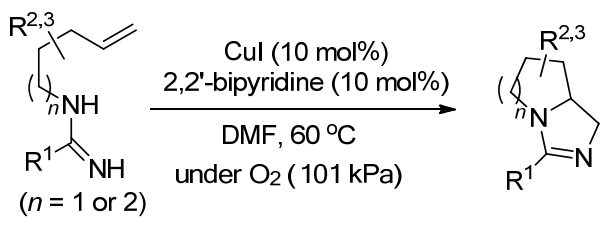

图式 5 铜催化的 $[3+2]$ 成环反应

Scheme $5 \mathrm{Cu}$-catalyzed [3+2]-annulation reaction

2014 年, Chemler 课题组 ${ }^{[13]}$ 再次报道了铜催化的烯 烃的二氨基化反应，且无论是分子内还是分子间反应的 底物范围，都是迄今为止报道的最为广泛的. 该氧化反 应以便宜易得的 $\mathrm{MnO}_{2}$ 促进, 以很好的产率和极好的对 映选择性生成了 2-氨基甲基二氢吲哚类化合物和四氢 吡咯类化合物(Scheme 6). 


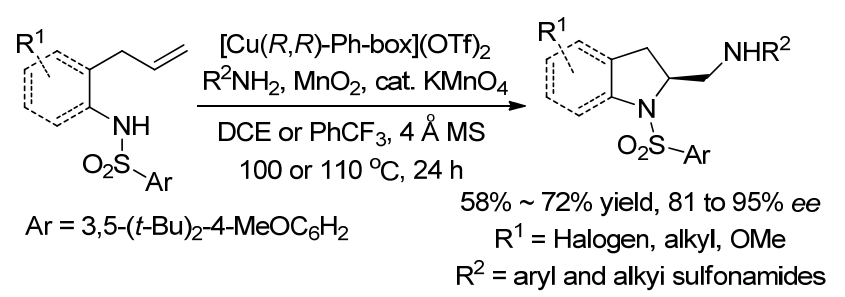

图式 6 铜催化烯烃的二氨化反应

Scheme $6 \mathrm{Cu}$-catalyzed alkene diamination

2015 年, Chemler 课题组 ${ }^{[14]}$ 又通过烯烃的二氨化反 应合成 2-氨甲基取代的 1,4-苯并二氮杂卓-5-酮类化合 物，都得到了很好的产率(Scheme 7).

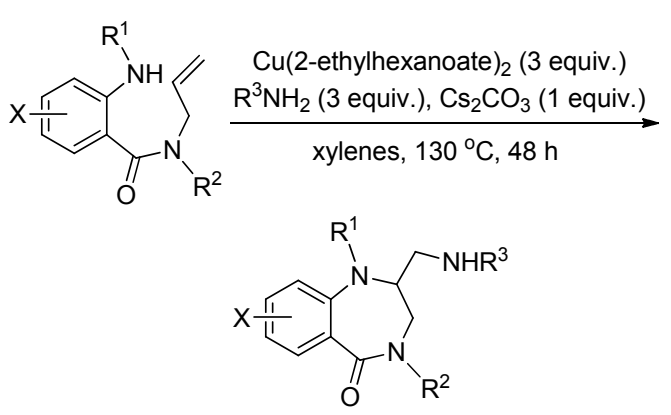

图式 7 铜催化烯烃的二氨化反应

Scheme $7 \mathrm{Cu}$-catalyzed alkene diamination

同年, Wang 课题组 ${ }^{[15]}$ 也对铜催化烯烃的二氨化反 应做了报道. 这是首例铜催化下直接将富电子氨基加成 到烯烃上的报道, 以吗啉-4-基苯甲酸酯作为亲电子的 氮源和氧化剂, $\mathrm{Cu}(\mathrm{OAc})_{2}$ 为催化剂, 在 $80{ }^{\circ} \mathrm{C}$ 下, $2 \mathrm{~h}$ 就 可以得到二氨化目标产物. 这是一个快速有效地合成二 氨化产物的方法(Scheme 8).

$\underset{\substack{\mathrm{O} H \\ \mathrm{OMe}}}{\mathrm{BzO}_{\mathrm{NTR}}-\mathrm{NR}^{1} \mathrm{R}^{2}} \underset{\substack{\mathrm{K} \mathrm{CO}_{3}(10 \mathrm{~mol} \%) \\ \mathrm{MTB}, 80^{\circ} \mathrm{C}, 2 \mathrm{~h}}}{\mathrm{Cu}(\mathrm{OAc})_{2}(10 \mathrm{~mol} \%)}$

图式 8 铜催化未活化烯烃的二氨化反应

Scheme 8 Cu-catalyzed diamination of unactivated alkene

2017 年, Chemler 课题组 ${ }^{[16]}$ 采用之前未使用过的不 饱和氨基甲酸酯作为铜催化二氨化反应的底物, 磺酰胺 类、苯胺类、苯甲酰胺、吗啉以及哌啶作为分子外部氨 源, 在温和的反应条件下以中等及以上的产率和非对映 选择性生成 3-氨甲基取代的异噁唑烷类化合物. 实验发 现, 与 2-烯丙基苯胺、4-戊烯基胺相比, 底物羟胺的高 反应活性很可能是由于羟胺的强亲核性、强自旋能力或 过渡态下较低的跨环张力, 高的反应活性确保了低的反 应温度, 反过来低的反应温度又使底物胺的范围更广 泛. 所以, 富电子胺与氧化条件下发生的铜催化烯烃的
二氨化反应并不是本质上不相容的, 相反, 温和的反应 条件, 特别是反应温度方面, 有利于其成功利用 (Scheme 9).

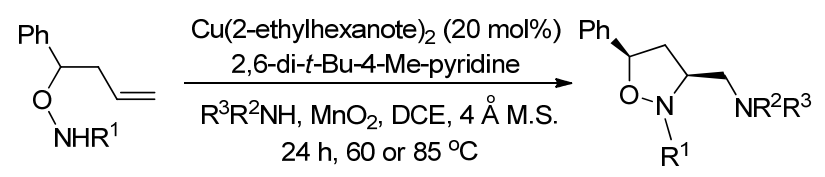

图式 9 铜催化烯烃的二氨化反应

Scheme 9 Cu-catalyzed alkene diamination

同年, Weng 课题组 ${ }^{[17]}$ 报道了 $\mathrm{Cu}$-TEMPO 催化的苯 乙烯的二氨化反应, 以 $N$-氟代双苯磺酰胺(NFSI)为唯一 的氮源，反应条件温和，涉及自由基反应历程(Scheme $10)$.

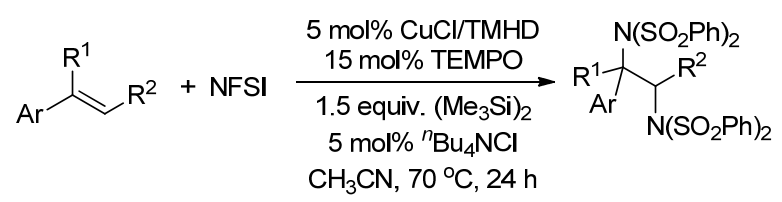

图式 10 铜催化烯烃的二氨化反应

Scheme $10 \mathrm{Cu}$-catalyzed alkene diamination

随后, $\mathrm{Liu}$ 课题组 ${ }^{[18]}$ 报道了在 $\mathrm{Cu}(\mathrm{I})$ /磷酸双催化作用 下烯烃的不对称自由基二氨化(Scheme 11)和叠氮胺化 反应(Scheme 12), 得到了高效率、显著的对映选择性、 优良的官能团相容性和广泛的底物范围的对映体富集 的 $\alpha$-三取代的吡咯烷类化合物. 此外, 得到的吡咯烷类 化合物可以显著地促进不对称 Michael 加成反应的对映 选择性，进一步展示了这一新反应方法的潜力(Scheme 13).

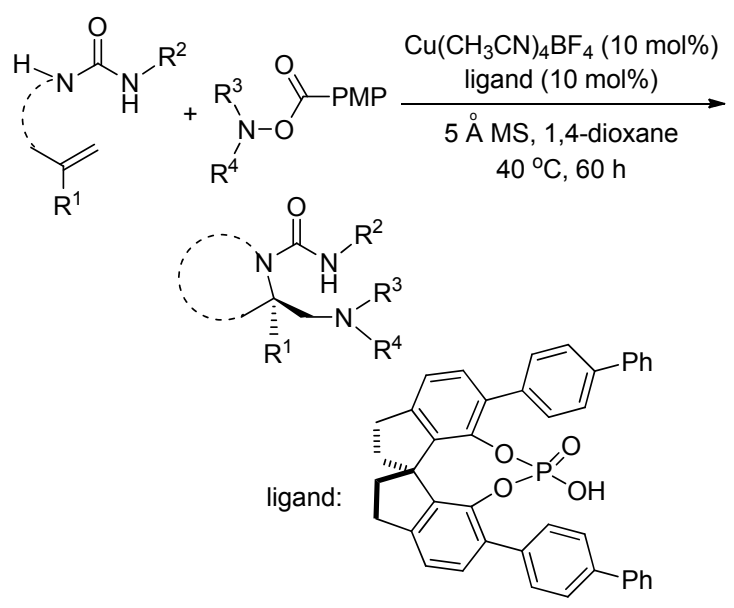

图式 11 催化烯烃的不对称自由基二氨化反应

Scheme 11 Catalytic asymmetric radical diamination of alkenes

2018 年, Wang 课题组 ${ }^{[19]}$ 报道了铜催化下 $\beta, \gamma$-不饱和 腙的二氨化反应, 以简单的胺作为外部氮源, 二甲基亚 砜(DMSO)作为氧化剂, 在温和的反应条件下生成吡唑 


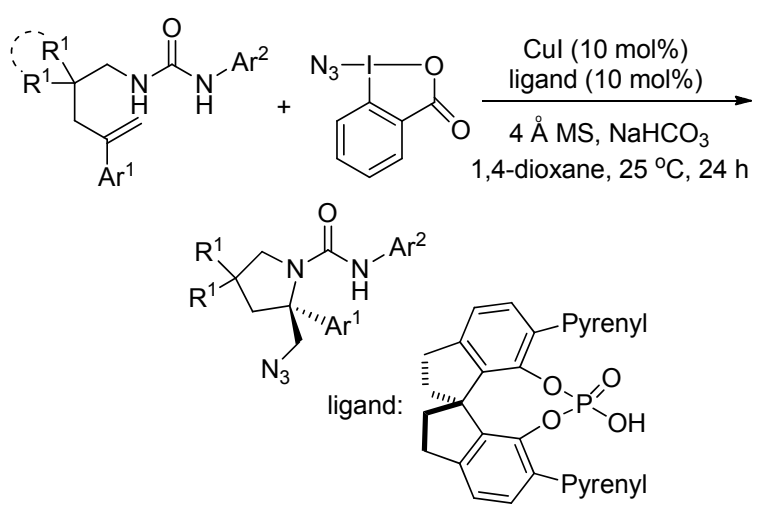

图式 12 催化烯烃的不对称自由基二氨化反应

Scheme 12 Catalytic asymmetric radical diamination of alkenes

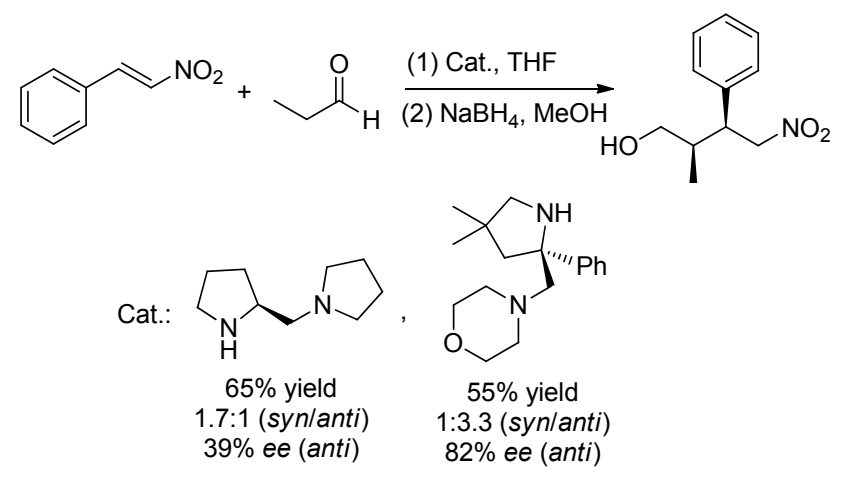

图式 13 催化烯烃的不对称自由基二氨化反应

Scheme 13 Catalytic asymmetric radical diamination of alkenes 啉类化合物, 这一类产物在有机合成及药物中都是重要 的组成部分(Scheme 14).<smiles>[R]NN=C([R])C(C)(C)C=C</smiles>

图式 14 铜催化下 $\beta, \gamma$-不饱和腙的二氨化反应 Scheme 14 Copper-catalyzed diamination of $\beta, \gamma$-unsaturated hydrazones

\subsection{2 烯烃的环化反应}

2015 年, Zeng 课题组 ${ }^{[20]}$ 首次报道了 $\mathrm{Cu}(\mathrm{II})$ 催化的 $N$ 烯丙基嫝的不对称分子内环化反应，为手性邻二胺双环 杂环化合物的快速合成提供了一种有效的方法, 其产率 为中等及以上, $e e$ 可高达 $98 \%$. 其中 $N, N$-螯合双齿噁唑 啉配体与碱金属碳酸锂一起对获得高对映选择性起了 至关重要的作用(Scheme 15).

\subsection{3 烯烃的氨氯化反应}

环邻氯胺酮广泛地存在于天然产物和生物活性化 合物中，是一种多用途的合成中间体 ${ }^{[21]}$.

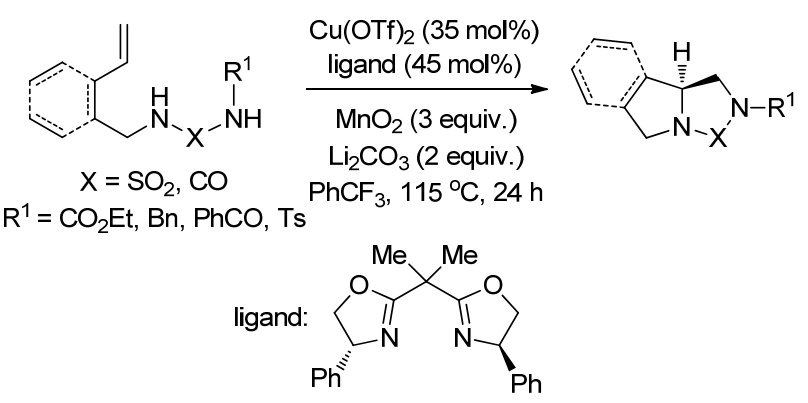

图式 15 铜催化 $N$-烯丙基艮的分子内环化反应

Scheme 15 Copper-catalyzed intramolecular cyclization of $\mathrm{N}$-alkenylureas

2016 年, Xu 课题组 ${ }^{[22]}$ 报道了 $\mathrm{Cu}$ (II)催化的烯烃的氨 氯化反应, $\mathrm{CuCl}_{2}$ 作为氧化剂和氯源，烯烃类、炔烃类、 丙二烯类各种碳一碳多重键化合物均适用于此反应. 反 应操作简单、底物拓展性强, 为生成邻氯氨化合物提供 了有效的途径(Scheme 16).

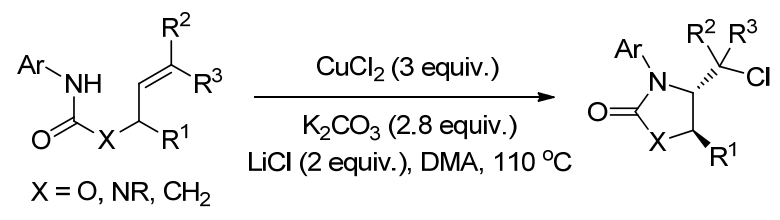

图式 16 铜催化烯烃的氨氯化反应

Scheme 16 Copper-catalyzed alkene aminochlorination reaction

\section{1 .4 烯烃的氨基炔基化}

碳一碳参键是有机化学中最有价值的官能团之一, 它作为有机合成中的合成中间体，具有多种反应活性， 在生物化学和材料科学中具有广泛的应用前景.

2017 年, Wang 课题组 ${ }^{[23]}$ 报道了温和条件下, 以乙 炔基苯碘酰酮(EBX)为试剂, 铜催化(催化剂用量仅为 1 $\mathrm{mol} \%$ )的烯烃的氨基炔化反应. 该反应不仅可以快速地 与炔基成键一步生成氮杂环化合物，而且对端烯和内烯 以及不同的炔基类化合物都具有很好的普适性. 可广泛 地应用于合成、生物共轭和分子成像技术(Scheme 17).

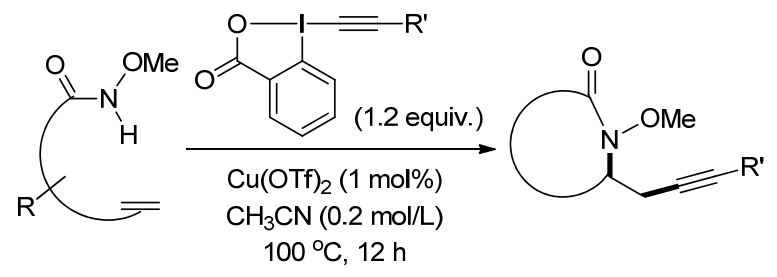

图式 17 铜催化烯烃的氨基炔化反应

Scheme 17 Copper-catalyzed aminoalkynylation of alkenes

\subsection{5 烯烃的氨基叠氮化}

同年, Wang 课题组 ${ }^{[24]}$ 又报道了 $\mathrm{CuOAc}$ 催化的未活 化烯烃的氨基叠氮化反应，反应将酰胺和叠氮从两个不 
同的氨基前体连接到端烯和内烯上，具有显著的区域选 择性和立体选择性. 机理研究表明, 这一二氨化反应是 先通过亲核氨基环化反应, 然后利用亲电的叠氮碘形成 分子间 $\mathrm{C}-\mathrm{N}$ 键. 这一反应途径与以往的叠氮碘烷引发 的烯烃功能化反应不同, 表明叠碘碘烷具有新的反应活 性. 此反应不仅可以快速引进各种功能化的二氨分子, 还能在复杂的含氮骨架上引入叠氮化合物, 从而促进其 在生物医学和材料研究中的研究和应用(Scheme 18).

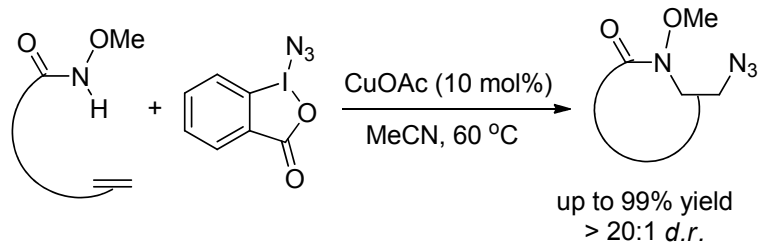

图式 18 铜催化未活化烯烃的氨基叠氮化反应

Scheme 18 Copper-catalyzed aminoazidation of unactivated alkenes

\subsection{6 烯烃的氨基烷基化}

2017, Xie 课题组 ${ }^{[25]}$ 报道了一种新的铜催化烯烃与 $\alpha$-澳代烷基酯和伯胺的串联环化反应, 合成了多取代的 吡咯烷-2-酮. 该反应一次形成三个新的化学键, 一个 $\mathrm{C}-\mathrm{C}$ 键和两个 $\mathrm{C}-\mathrm{N}$ 键, 是首个三组分的 $[2+2+1]$ 成 环的烯烃的双官能团化反应, 包括氨基烷基化反应和酰 胺化反应, 且研究表明该反应历经自由基历程(Scheme 19).

$$
\underset{R^{2}}{R^{1}}=L_{\mathrm{CO}_{2} R^{6}}^{R^{3}}+\mathrm{Br} \underset{\mathrm{R}^{5}}{\stackrel{\mathrm{R}^{4}}{-}}
$$

图式 19 铜催化烯烃的分子间氨基烷基化反应

Scheme 19 Copper-catalyzed intermolecular amino-alkylation of alkenes

\subsection{7 烯烃的硼胺化反应}

2017 年, Liao 课题组 ${ }^{[26]}$ 报道了以手性亚砜磷配体, $\mathrm{CuCl}$ 为催化剂的苯乙烯的不对称硼胺化反应, 以亲电 性胺试剂和联硼酸频哪醇酯分别作为氮源和硼源, 合成 的手性 $\beta$-氨基烷基硼酯可转化为有用的手性 $\beta$-羟胺类 化合物(Scheme 20).

\subsection{8 烯烃的碳氨化反应}

2018 年, Hull 课题组 ${ }^{[27]}$ 通过对 $\alpha$-卤代羰基化合物和 胺类化合物进行研究, 报道了铜催化的三组分的碳胺化 反应. 它可以将易得的烯烃、功能化的烷基卤代物与胺

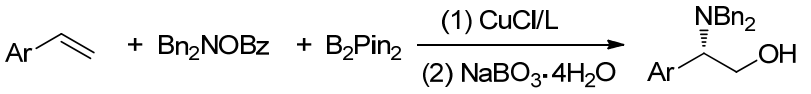

图式 20 铜催化的苯乙烯的不对称嗍胺化反应

Scheme 20 Cu-catalyzed enantioselective aminoboration of styrenes

偶联在一起, 且三组分的反应范围都很广, 产率由一般 到很好. 初步的机理研究发现反应经历碳自由基历程 (Scheme 21).

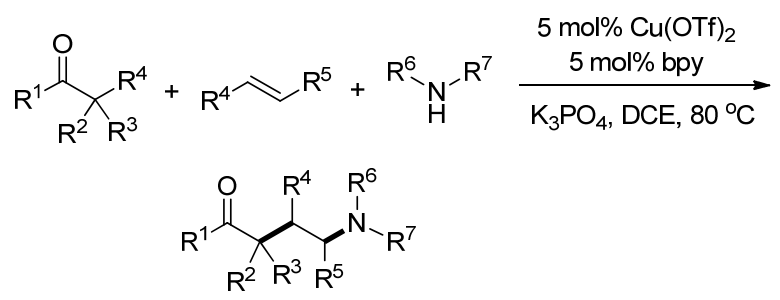

图式 21 铜催化的三组分的碳胺化反应

Scheme 21 Cu-catalyzed three-component carboamination of alkenes

\section{2 烯烃的芳基化反应}

\subsection{1 烯烃的芳氨化反应}

2007 年, Chemler 课题组 ${ }^{[28]}$ 报道了一种新颖的铜催 化烯烃的不对称芳氨化反应，反应为芳基磺酰胺对分子 内末端烯烃的加成, 从而得到手性磺内酰胺. $\mathrm{MnO}_{2}$ 作为 氧化剂使催化循环顺利地实现, 并以较高的产率得到了 目标产物. 用手性双噁唑啉配体, 得到了高达 94\%的 ee 值(Scheme 22).

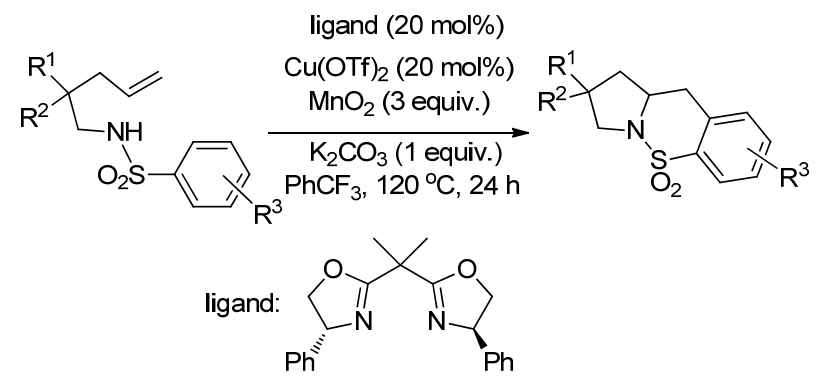

图式 22 铜催化烯烃的不对称芳氨化反应

Scheme $22 \mathrm{Cu}$-catalyzed enantioselective carboamination of alkenes

烯烃的分子内碳氨化反应是合成氮杂环的有效方 法. 2010 年, 该课题组 ${ }^{[29]}$ 又报道了铜催化的烯烃的分子 内对映选择性芳基氨化反应，使用同样手性双噁唑啉配 体, 得到的产物同时具有两个手性中心, 且得到了高达 $20: 1$ 的 $d r$ 值与 $97 \%$ 的 ee 值(Scheme 23).

2013 年, Kanai 课题组 ${ }^{[30]}$ 报道了铜催化的分子间的 芳氨化反应，以末端烯烃与 NFSI 反应，NFSI 同时提供 芳源和氮源，得到了产率达 $91 \%$ 的磺内酰胺类目标产 


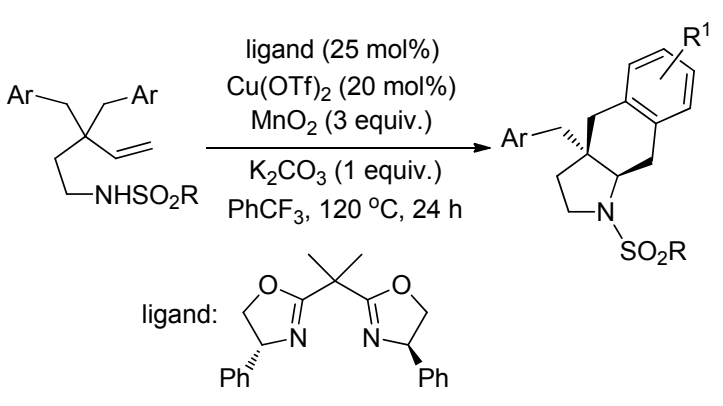

图式 23 铜催化烯烃的分子内芳氨化反应

Scheme 23 Cu-catalyzed intramolecular carboamination of alkenes

物, 且反应有较好的底物范围(Scheme 24).

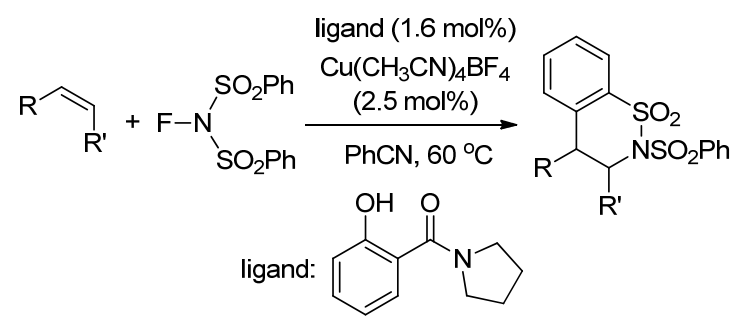

图式 24 铜催化烯烃的分子间芳氨化反应

Scheme 24 Cu-catalyzed intermolecular carboamination of alkenes

光学纯的 2,2-二芳基乙胺骨架作为药理学中多巴胺 受体激动剂的重要构造, 广泛地存在于生物活性分子及 药物中. 因此, 对映选择性的 2,2-二芳基乙胺骨架是高 度需求的, 但是, 关于这一物质的有效的合成方法报道 太少.

2017 年, Lin 课题组 ${ }^{[31]}$ 报道了烯烃的分子间不对称 芳基氨基化反应, 以一价铜为催化剂, $N$-氟代- $N$-芳基磺 酰胺为氨源, 与 $\mathrm{Cu}(\mathrm{I})$ 反应释放出氨自由基, 加成到烯烃 后产生的苄基自由基与 $\mathrm{L}^{*} \mathrm{Cu}^{\mathrm{II}} \mathrm{Ar}$ 偶联得到对映选择性 的芳基化产物(Scheme 25). 反应具有很好的对映选择 性和底物普适性, 生成了可用于合成生物活性分子的

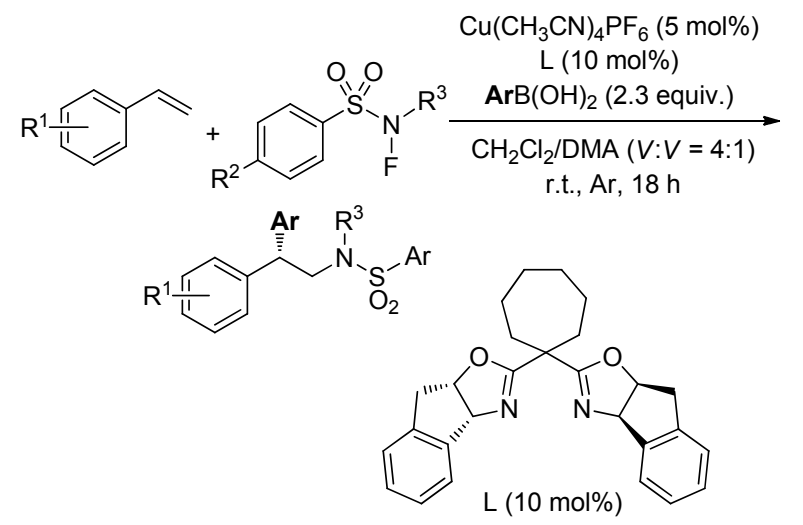

图式 25 铜催化烯烃的分子间不对称芳基氨基化反应 Scheme 25 Asymmetric copper-catalyzed intermolecular aminoarylation of styrenes
2,2-二芳基乙胺类化合物.

\subsection{2 烯烃的芳基醚化反应}

2012 年, Chemler 课题组 ${ }^{[32]}$ 进一步报道了铜催化的 烯烃分子内芳基醚化反应生成稠环和桥环两种四氢呋 喃类化合物，该反应具有很好的官能团容忍性，但手性 控制无法实现(Scheme 26).

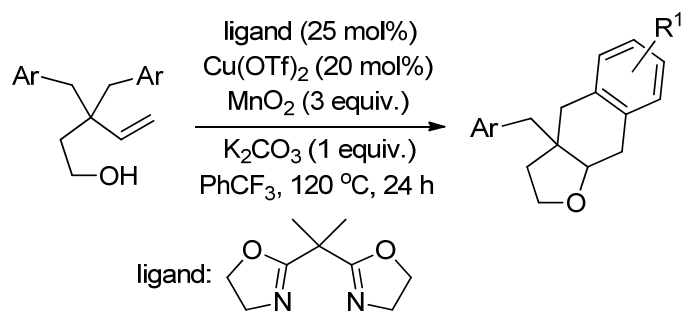

图式 26 铜催化烯烃的分子内芳基醚化反应

Scheme 26 Copper-catalyzed intramolecular alkene carboetherification

\subsection{3 烯烃的芳基苄基化反应}

2013 年, Duan 课题组 ${ }^{[33]}$ 报道了铜催化丙烯酰胺类 化合物的芳基茮基化反应，生成氧化吲哚衍生物，得到 了高达 $96 \%$ 的产率，且很好地体现了原子经济性 (Scheme 27).<smiles>[R3]C(=C)C(=[O+])N([R])c1cc[R1](C)cc1</smiles>

图式 27 铜催化丙烯酰胺类化合物的芳基芐基化反应

Scheme 27 Copper-catalyzed benzylarylation of acrylamides

\section{2 .4 烯烃的二芳基化反应}

同年, $\mathrm{Li}^{[34]} 、 \mathrm{Fu}^{[35]} 、 \mathrm{Zhao}^{[36]}$ 课题组均报道了铜催化 的烯烃的双芳基化反应，以高价碘试剂为芳基源生成 3,3-二取代的氧化吲哚衍生物(Scheme 28).

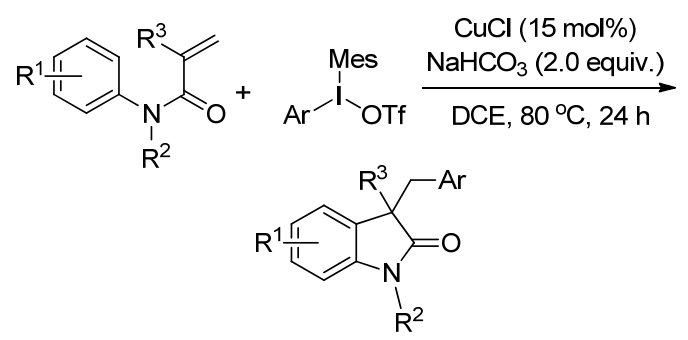

图式 28 铜催化烯烃的双芳基化反应

Scheme 28 Copper-catalyzed bis-arylations of alkenes

\section{3 烯烃的三氟甲基化反应}

含氟类化合物因其独特的生物活性，在材料化学、 药物化学等多个领域得到了极其广泛的应用，而三氟甲 
基具有较低的生物毒性及较强的亲脂性, 因此研究者们 对其有了越来越多的兴趣 ${ }^{[37]}$.

\subsection{1 烯烃的三氟甲基硫氰化反应}

硫氰类化合物是一类重要的反应中间体，它可以用 于合成具有生物活性的分子, 也可以合成橡胶硫化的加 速剂.

2015 年, Liu 课题组 ${ }^{[38]}$ 以三甲硅烷基异氰酸酯 (TMSNCS)作为硫氰源, 以 Togni 试剂作为三氟甲基源, 在 $\mathrm{Cu}(\mathrm{I})$ 的催化作用下, 同时将硫氰基和三氟甲基引入 分子中. 这一反应化学选择性高、反应条件温和、底物 普适性及官能团兼容性都比较好. 反应历经自由基反应 历程, 先生成三氟甲基自由基, 之后对烯烃加成生成 $\beta-\mathrm{CF}_{3}$ 的苠基自由基, 最后与 $\mathrm{TMSNCS}$ 反应形成 $\mathrm{C}-\mathrm{S}$ 键(Scheme 29).

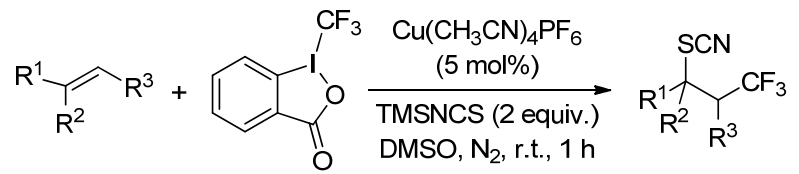

图式 29 铜催化烯烃的三氟甲基硫氰化反应

Scheme 29 Copper-catalyzed intermolecular trifluoromethylthiocyanation of alkenes

\subsection{2 烯烃的芳基三氟甲基化反应}

同年, Sodeoka 课题组 ${ }^{[39]}$ 报道了 $\mathrm{CuI} /$ Togni 试剂催化 的烯烃的芳基三氟甲基化反应，以较高的产率得到了三 氟甲基化的碳环化合物和杂环化合物(Scheme 30).

2014 年, Liang 课题组 ${ }^{[40]}$ 也报道了铜催化的分子内 的芳基三氟甲基化反应，以 $N$-芳基丙烯酰胺类化合物 为原料, 以便宜易得的 Langlois 试剂为三氟甲基源, 室 温条件下在水相中发生自由基反应历程生成目标产物 (Scheme 31).

\subsection{3 烯烃的氨基三氟甲基化反应}

2013 年, Sodeoka 课题组 ${ }^{[41]}$ 报道了铜催化的烯基胺 的三氟甲基化反应，包括烯丙基苯胺衍生物的 $\mathrm{N}$-迁移

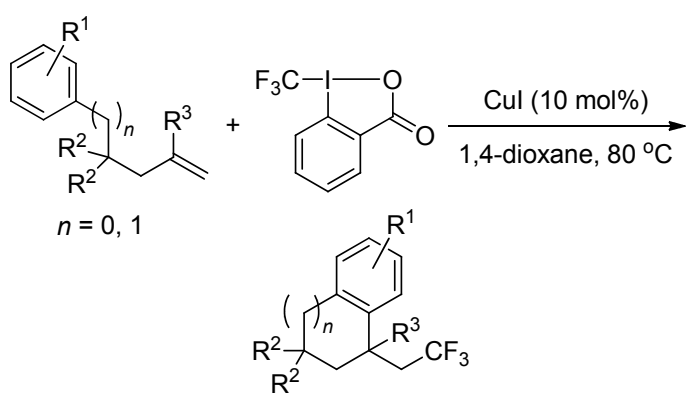

图式 30 铜催化烯烃的芳基三氟甲基化反应

Scheme 30 Copper-catalyzed alkene trifluoromethylation<smiles>[R]C(=C)C(=O)N([R])c1cc[R1]cc1</smiles>

图式 31 铜催化 $\mathrm{N}$-芳基丙烯酰胺的芳基三氟甲基化反应 Scheme 31 Copper-catalyzed trifluoromethylation of $\mathrm{N}$-arylacrylamides

氧三氟甲基化反应、氨基三氟甲基化反应及三组分一锅 法偶联反应. 这些高效的反应将为含有 $\beta$-三氟甲生物活 性化合物的合成开辟一条新的途径(Scheme 32).

2014 年, Tan 和 $\mathrm{Liu}$ 课题组 ${ }^{[42]}$ 首次报道了以 (TMS) $\mathrm{CF}_{3}$ 为 $\mathrm{CF}_{3}$ 源的铜催化分子内未活化烯烃的氨基 三氟甲基化反应. 该反应与以往的反应相比，不仅扩大 了底物范围, 避免了使用昂贵的亲电 $\mathrm{CF}_{3}$ 试剂和光氧化 还原策略，而且提高了官能团的容忍性，体现了其在医 药化学及材料科学方面的应用性(Scheme 33).

同年, Liu 课题组 ${ }^{[43]}$ 又报道了以铜作为催化剂, Togni 试剂为三氟甲基源，未活化烯烃与多种氨基亲核试剂 的氨基三氟甲基化反应，以优良的产率得到了吡咯烷类 及二氢吲哚类化合物(Scheme 34).

2016 年 $\mathrm{Liu}$ 课题组 ${ }^{[44]}$ 首次报道了 $\mathrm{CuCl}$ 催化下烯烃 的不对称自由基氨基三氟甲基化反应. 该反应以新奇、 简单、高效的方法直接获得了各种含 $\mathrm{CF}_{3}$ 取代基的吡咯

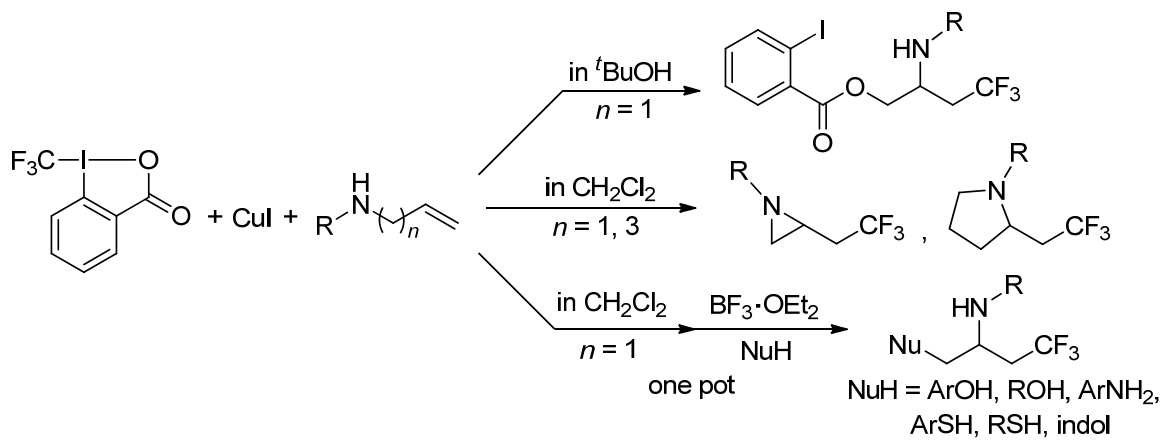

图式 32 合成 $\beta$-三氟甲基胺的三氟甲基化反应

Scheme 32 Trifluoromethylation reactions for the synthesis of $\beta$-trifluoromethylamines 


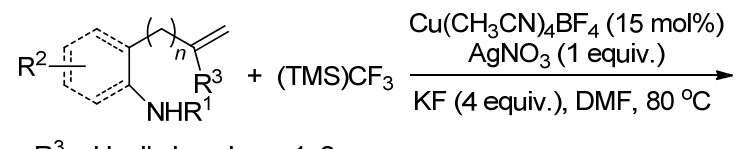

$\mathrm{R}^{3}=\mathrm{H}$, alkyl, aryl; $n=1,2$<smiles>[R][R]1ccc2c(c1)C([R])(CC(F)(F)F)N2[R1]</smiles>

图式 33 铜催化未活化烯烃的氨基三氟甲基化反应 Scheme 33 Copper-catalyzed aminotrifluoromethylation of unactivated alkenes

$$
\text { (25 mol\%) }
$$

图式 34 铜催化未活化烯烃的氨基三氟甲基化反应

Scheme 34 Copper-catalyzed aminotrifluoromethylation of unactivated alkenes

烷骨架化合物, 且该反应具有极好的效率、显著的对映 选择性及官能团容忍性. 而且这一反应的成功不仅仅归 功于 $\mathrm{Cu}(\mathrm{I})$ /磷酸催化体系, 含两个 $\mathrm{N}-\mathrm{H}$ 的尿素作为亲 核试剂和导向基(Scheme 35).

2016 年, Wang 课题组 ${ }^{[45]}$ 报道了一种以酰胺为亲核 试剂的铜催化烯烃的氨基三氟甲基化反应. 该方法可以
以较好的产率生成各种含 $\mathrm{CF}_{3}$ 的内酰胺，反应条件温和， 具有很广的底物范围. 为制备含 $\mathrm{CF}_{3}$ 的内酰胺提供了一 种有价值的方法, 在医药和农用化学品方面具有很大的 应用价值(Scheme 36).

2017 年, Liu 课题组 ${ }^{[46]}$ 再次报道了铜催化的不对称 自由基氨基氟烷基化反应和氨基二氟甲基化反应. 该反 应以商业可用的氟烷基磺酰氯为自由基源，与烯烃反 应，均以极好的产率和对映选择性获得四种类型 $(\beta$-全 氟丁基、 $\beta$-三氟甲基、 $\beta$-二氟乙酰基及 $\beta$-二氟甲基) $\alpha$-叔 碳吡咯烷骨架化合物. 该反应成功的关键不仅在于引入 了 $\mathrm{CuBr}$ 手性磷酸双催化体系, 而且还在于使用碳酸银 抑制由原位生成的 $\mathrm{HCl}$ 引起的强背景反应和侧氢化胺 反应. 广泛的底物范围、极好的官能团容忍性、产品多 功能化使该方法更加实用(Scheme 37).

\subsection{4 烯烃的氧三氟甲基化反应}

2012 年, Buchwald 课题组 ${ }^{[47]}$ 报道了 $\mathrm{Cu}(\mathrm{I}) / 2,2^{\prime}$-联喹 啉催化体系下发生的一种温和、通用、简便的未活化烯 烃的氧三氟甲基化反应，这一方法从简单的起始原料来 合成有用的含 $\mathrm{CF}_{3}$ 骨架的化合物. 其中, Togni 试剂作为 三氟甲基源, 羧酸、醇类、酚类均可作为此反应条件下 的亲核试剂. 随后, 该课题组 ${ }^{[48]}$ 利用手性双噁唑啉配体 研究了以上反映的对映选择性, 并获得了较高的 $e e$ 值 (Scheme 38).

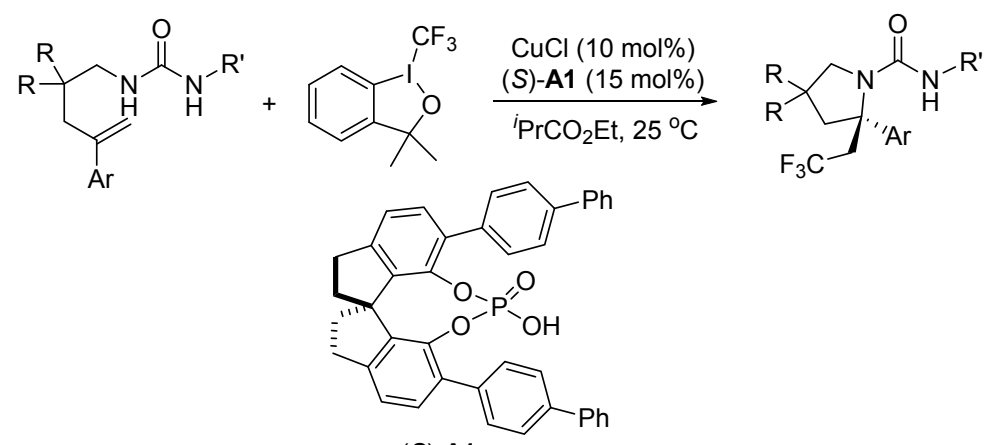

(S)-A1

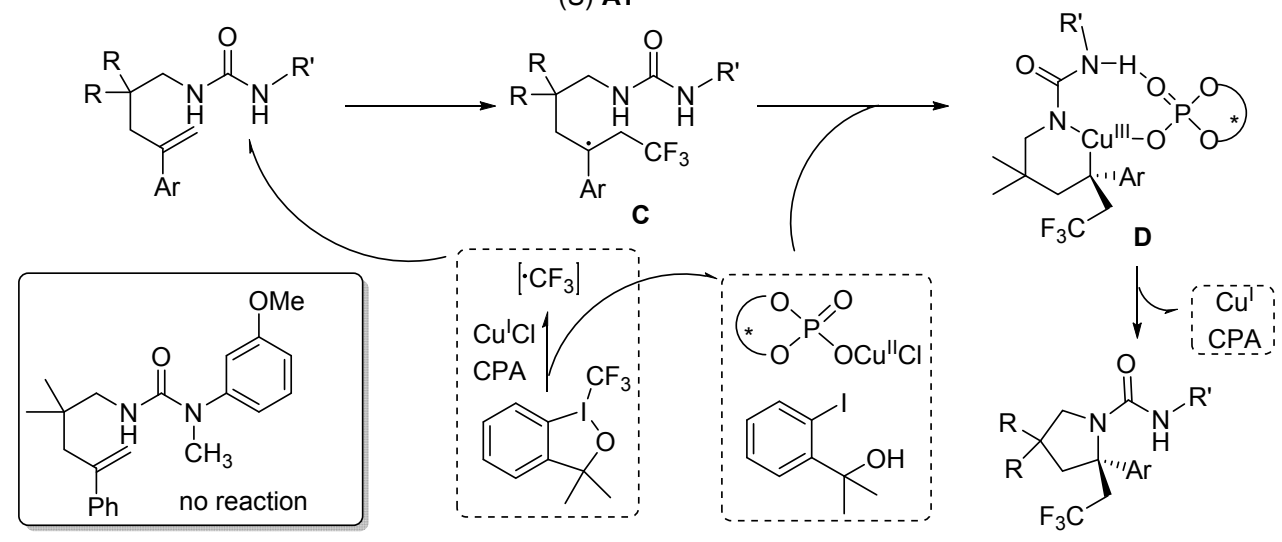

图式 35 烯烃的不对称自由基氨基三氟甲基化反应

Scheme 35 Asymmetric radical aminotrifluoromethylation of alkenes 


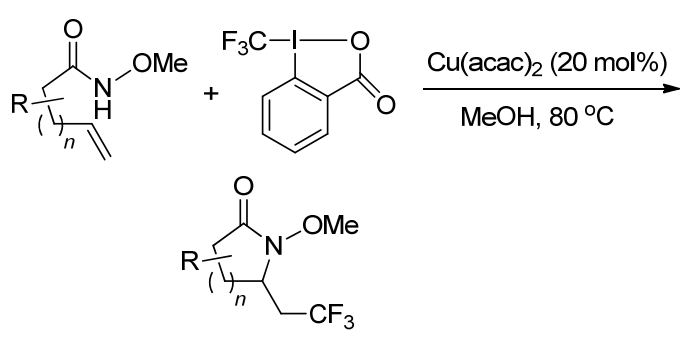

图式 36 铜催化烯烃的氨基三氟甲基化反应

Scheme 36 Copper-catalyzed aminotrifluoromethylation of alkenes

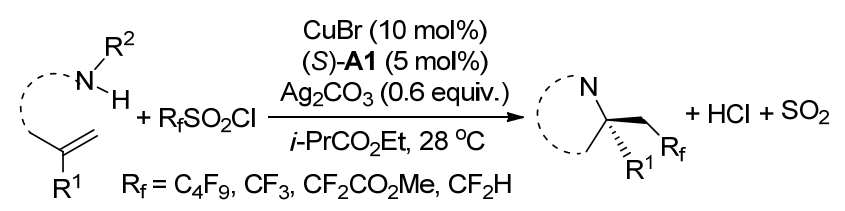<smiles>O=P(O)(O)c1c(-c2ccc(-c3ccccc3)cc2)ccc2c1C1Oc3c(-c4ccccc4)ccc(c31)CC2</smiles>

(S)-A1

图式 37 烯烃的不对称自由基氨基氟烷基化反应和氨基二氟 甲基化反应

Scheme 37 Catalytic asymmetric radical aminoperfluoroalkylation and aminodifluoromethylation of alkenes

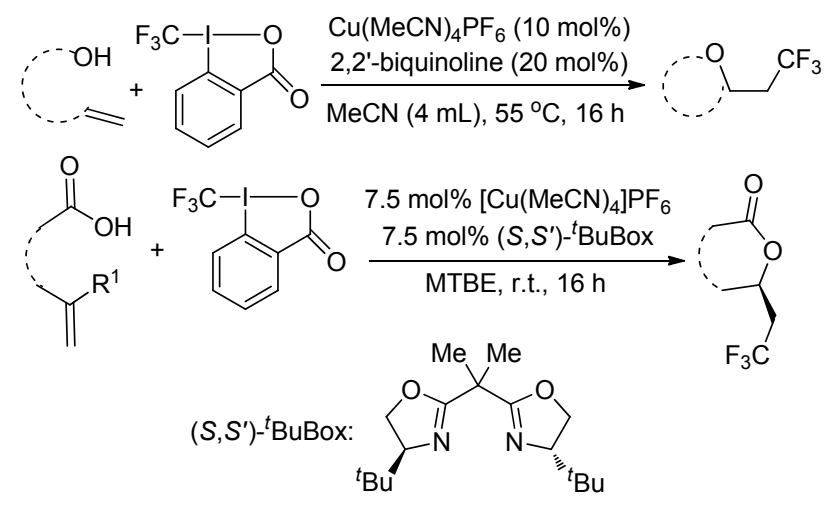

图式 38 铜催化未活化烯烃的氧三氟甲基化反应

Scheme 38 Copper-catalyzed aminotrifluoromethylation of unactivated alkenes

随后, 2013 年, Qing 课题组 ${ }^{[49]}$ 报道了铜催化的烯烃 与三氟甲基磺酸钠和羟肟酸的三组分氧三氟甲基化反 应, 该反应以 $\mathrm{CuSO}_{4} \cdot 5 \mathrm{H}_{2} \mathrm{O}$ 为催化剂, 采用稳定廉价的 $\mathrm{NaSO}_{2} \mathrm{CF}_{3}$ 作为三氟甲基源, 反应条件温和, 具有良好 的官能团容忍性(Scheme 39).

2016 年, $\mathrm{Yu}$ 课题组 ${ }^{[50]}$ 首次利用无毒易得的温室气 体 $\mathrm{CO}_{2}$ 与烯丙胺在铜催化作用下, 和 Togni's 试剂发生 氧三氟甲基化反应，高效高选择性地合成具有生理活性<smiles>[R]C=C([R])[CH+][R]</smiles>

图式 39 铜催化烯烃的氧三氟甲基化反应

Scheme 39 Copper-catalyzed aminotrifluoromethylation of alkenes

的含三氟甲基的 2-噁唑烷酮类化合物. 特别值得注意的 是, 这是在氧化还原中性及温和的条件下发生的高化学 选择性、高区域选择性及高非对映选择性的反应. 此外, 该反应具有良好的官能团兼容性及底物拓展性，易实现 产品的多样化(Scheme 40).

$$
\text { r.t., 16 he, }
$$

图式 40 烯丙胺与二氧化碳的选择性氧三氟甲基化反应 Scheme 40 Selective oxytrifluoromethylation of allylamines with $\mathrm{CO}_{2}$

2017 年, Liu 课题组 ${ }^{[51]}$ 以非手性吡啶作为辅助配体, 在 $\mathrm{CuI} /$ 磷酸双催化作用下，首次实现了烯烃与醇的不对 称自由基氧三氟甲基化反应. 这一反应条件温和，底物 范围广, 具有极好的官能团容忍性, 为获得对映选择性 的三氟甲基取代的四氢呋喃类化合物提供了一种独特 的、直接的途径(Scheme 41).
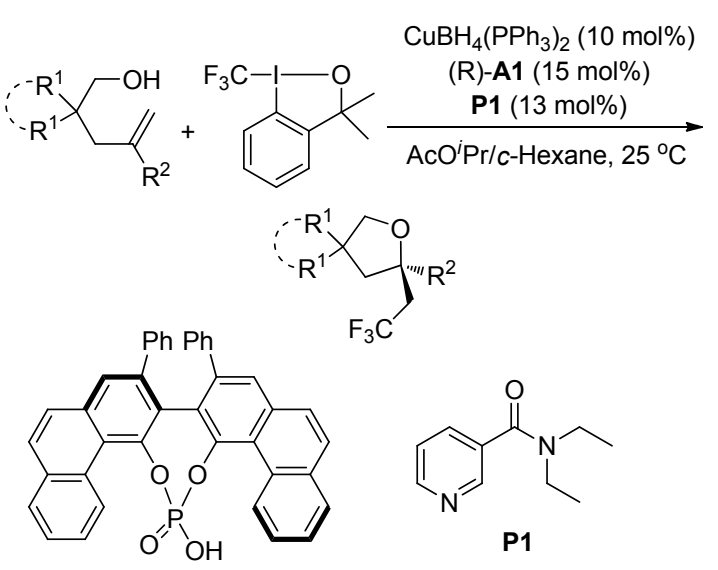

(R-A1)

图式 41 烯烃与醇的不对称自由基氧三氟甲基化反应 Scheme 41 Enantioselective radical oxytrifluoromethylation of alkenes with alcohols

2018 年, Liu 课题组 ${ }^{[52]}$ 通过铜催化烯烃肜化合物与 Togni's 试剂的不对称自由基氧三氟甲基化反应, 得到 
了对映选择性的 $\alpha$-叔碳立体中心的含 $\mathrm{CF}_{3}$ 的异噁唑啉类 化合物. 该反应成功的关键在于合理设计以金鸡纳-生 物碱基磺胺为中性/阴离子混合配体, 有效控制包含游 离烷基自由基的铜催化反应的立体化学. 将产物转化为 含 $\mathrm{CF}_{3}$ 基团的手性 1,3-氨基醇, 进一步说明该方法的实 用性(Scheme 42).

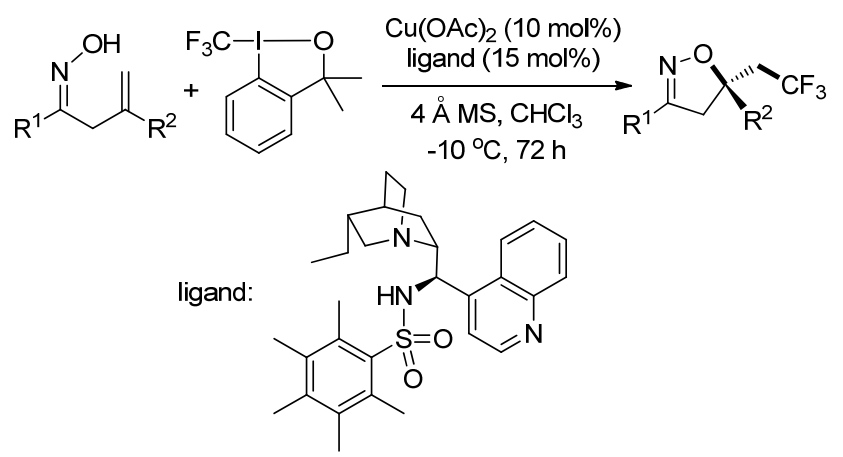

图式 42 烯烃肜类化合物的不对称自由基氧三氟甲基化反应 Scheme 42 Asymmetric radical oxytrifluoromethylation of alkenyl oximes

\subsection{5 烯烃的酰基三氟甲基化反应}

2016 年, Liu 课题组 ${ }^{[53]}$ 首次成功研发了烯烃的自由 基 1,2-双官能团化型甲酰化反应. 该反应由未活化烯 烃的三氟甲基化、叠氮化、磺酰化、全氟烷基化或二氟 甲基化引发 1,2-、1,4-和 1,5-甲酰自由基迁移而发生. 这 是一种新颖的、可持续的自由基反应, 且能以良好的效 率、显著的选择性和良好的官能团容忍性生成 $\beta$-官能团 化醛类化合物. 这一方法可用于生成苯并九、十、十一 元环化合物以及多功能化的桥环化合物(Scheme 43).

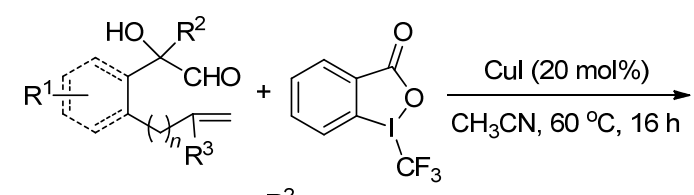

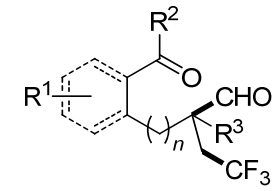

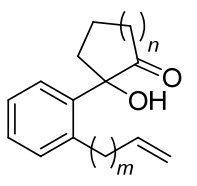

$$
\frac{\left[\operatorname { l r } \left(\mathrm{ppy}_{2}(\mathrm{dtbbpy}) \mathrm{PF}_{6}(1 \mathrm{~mol} \%)\right.\right.}{\mathrm{Na}_{2} \mathrm{HPO}_{4}(2.0 \text { equiv. })}
$$

$$
m=0,1
$$

$n=1,2,3$

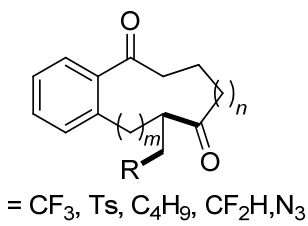

图式 43 烯烃的 1,2-甲酰/羰基官能团化反应

Figure 43 1,2-Formyl/carbonyl functionalization of alkenes
2017 年, Zhu 课题组 ${ }^{[54]}$ 首次报道了铜催化烯烃的酰 基三氟甲基化反应，以优良的产率和非对映选择性得到 了三氟甲基狮酮类化合物及相关的环酮类化合物，为生 物活性化合物的合成提供了有效的方法(Scheme 44).

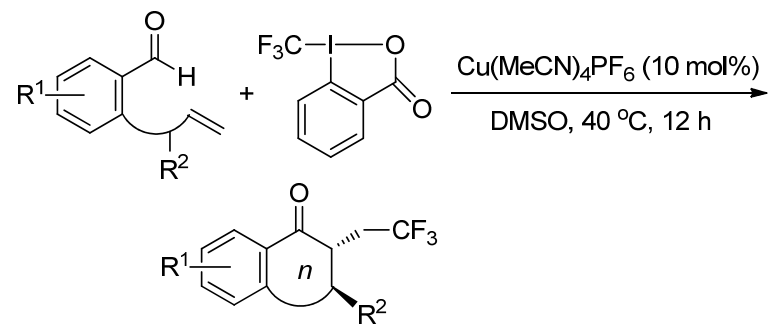

图式 44 铜催化烯烃的酰基三氟甲基化反应

Scheme 44 Copper-catalyzed acyltrifluoromethylation of alkenes

\subsection{6 烯烃的三氟甲基炔基化反应}

2018 年, Liu 课题组 ${ }^{[55]}$ 报道了一种新颖的铜对映选 择性催化的苯乙烯的三氟甲基炔基化反应，反应在非常 温和的条件下通过自由基传递过程以高产率和极好的 对映选择性获得了结构多样的含 $\mathrm{CF}_{3}$ 基团的炔基化合 物. 该反应底物范围广，官能团容忍性好. 此外获得的 三氟甲基炔基化产物可以转化为具有综合用途的手性 末端炔烃、丙二烯、 $Z$-烯烃及 $C_{3}$ 修饰的非甾体抗炎药 (Scheme 45).
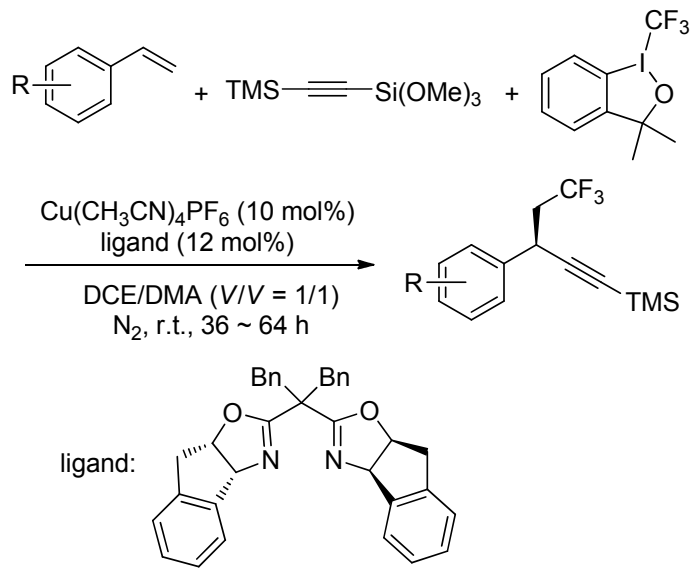

图式 45 铜催化苯乙烯的三氟甲基炔基化反应 Scheme 45 Copper-catalyzed trifluoromethylalkynylation of styrenes

\section{4 烯烃的叠氮化反应}

有机叠氮化合物是一类重要的结构单元和有机活 性中间体 ${ }^{[56]}$, 可以在有机合成中进行多样性转换, 例如 转化为异氧、胺或者其它杂环化合物，所以叠氮化合物 可以作为天然产物和生物活性化合物的前体，合成药 物、分子配体及生物活性化合物. 此外，有机叠氮化合 物在多肽化学、聚合物合成及材料科学中都有非常广泛 的应用 ${ }^{[57]}$. 


\subsection{1 烯烃的氧叠氮化反应}

2014 年, Jiao 课题组 ${ }^{[58]}$ 报道了铜催化 3-取代吲哚的 氧叠氮化反应和烷氧化叠氮化反应, 这一反应条件温 和, 铜催化下高价碘叠氮试剂产生叠氮自由基, 然后迅 速地经过脱芳构化作用以优良的产率得到目标产物，反 应不需要加入任何的碱或配体(Scheme 46).

$$
\begin{aligned}
& \text { 管 } \\
& \overbrace{N_{R^{2}}^{O}}^{N_{3}}
\end{aligned}
$$

图式 46 铜催化吲哚的氧叠氮化反应和烷氧化叠氮化反应

Scheme 46 Copper-catalyzed oxoazidation and alkoxyazidation of indoles

随后, $\mathrm{Xu}$ 课题组 ${ }^{[59]}$ 报道了烯烃的分子内自由基氧 叠氮化反应, 以便宜易得的 $\mathrm{TMSN}_{3}$ 作为叠氮试剂, 有机 碱(如 $\mathrm{NaOAc} 、 \mathrm{Na}_{2} \mathrm{CO}_{3}$ ) 可有效地促进肜自由基的形成, 在温和的反应条件下, 以优良的产率生成叠氮取代的异 啞唑啉类化合物(Scheme 47).

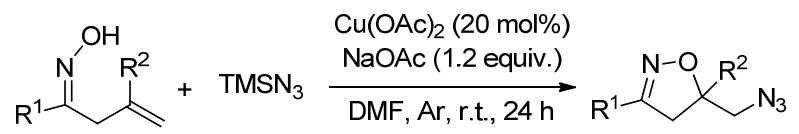

图式 47 铜催化未活化烯烃的氧叠氮化反应

Scheme 47 Copper-catalyzed oxyazidation of unactivated alkenes

2015 年, Buchwald 课题组 ${ }^{[60]}$ 报道了通过铜催化的 烯烃的自由基氧化官能团化作用，对映选择性地合成功 能化内酯的反应, 其中含有链烯烃羧酸的分子内氧叠氮 化反应. 反应用了催化量的 $\mathrm{Cu}(\mathrm{MeCN})_{4} \mathrm{PF}_{6} 、 \mathrm{TMSN}_{3}$ 和 $\mathrm{PhI}(\mathrm{OAc})_{2}$ 来促进反应的进行, 其中叠氮自由基和 $\mathrm{Cu}(\mathrm{II})$ 络合物就是由 $\mathrm{Cu}(\mathrm{I})$ 与 $\mathrm{TMSN}_{3}$ 和 $\mathrm{PhI}(\mathrm{OAc})_{2}$ 发生氧化还 原反应得到的, 之后叠氮自由基加成到烯烃上形成三级 碳自由基，而三级碳自由基在手性 Box 配体的作用下， 立体选择性地与 $\mathrm{Cu}^{\mathrm{II}}$ 部分结合, 最后 $\mathrm{C}-\mathrm{O}$ 还原消除生 成内酯目标产物和 $\mathrm{Cu}^{\mathrm{I}}$ 催化剂(Scheme 48).

\section{4 .2 烯烃的二叠氮化反应}

2015 年, Loh 课题组 ${ }^{[61]}$ 报道了铜催化烯烃的氧叠氮 化反应和二叠氮化反应, Togni 试剂为叠氮自由基源, 反 应条件温和, 官能团兼容性强, 以较好的产率生成了芳 基叠氮化合物(Scheme 49).

2017 年, Bao 课题组 ${ }^{[62]}$ 报道了在乙腈或水溶液中, 无配体的情况下, 以 $\mathrm{TMSN}_{3}$ 为氮源的铜催化的烯烃的 二叠氮化反应. 反应条件温和, 具有很广的底物范围,

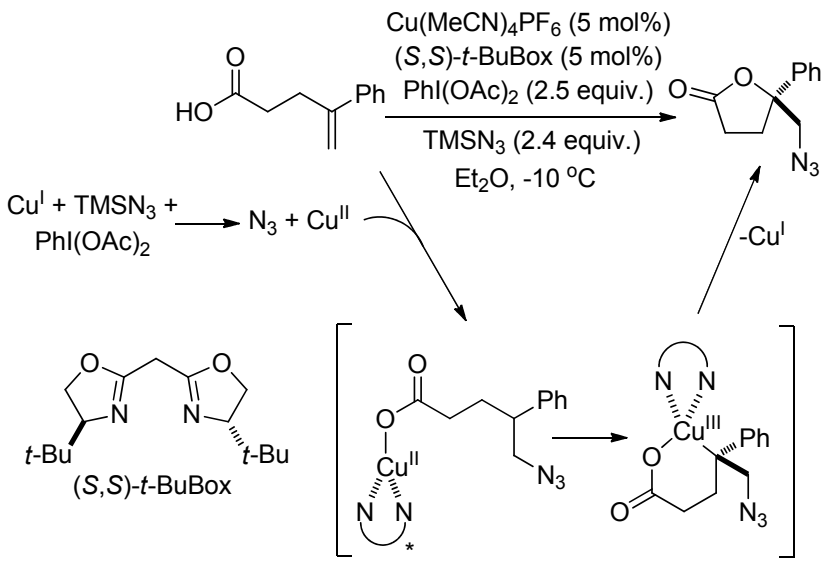

图式 48 铜催化烯烃的对映选择性氧叠氮化反应 Scheme 48 Cu-catalyzed enantioselective alkene oxyazidation

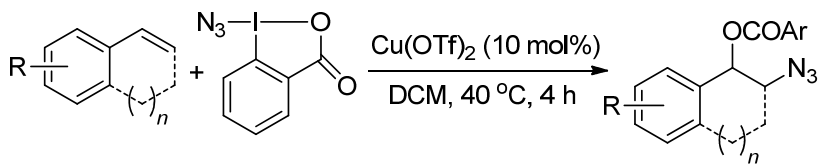<smiles>[R]C=CC(=O)OC(=O)c1ccccc1C(=O)OI(N)N</smiles>

图式 49 铜催化烯烃的氧叠氮化反应和二叠氮化反应 Scheme $49 \mathrm{Cu}$-catalyzed oxyazidation and diazidation of styrenes

芳基乙烯、未活化的烯烃及双烯类均适用于此反应. 其 在有机溶剂或水溶液中均可反应的条件，为实际应用提 供了更多的可能(Scheme 50).

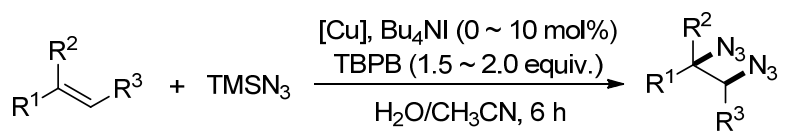

图式 50 铜催化烯烃的二叠氮化反应

Scheme $50 \mathrm{Cu}$-catalyzed diazidation of styrenes

\subsection{3 烯烃的叠氮氧甲基化}

2017 年, Zhu 课题组 ${ }^{[63]}$ 报道了首例乙腈和叠氮化钠 参与的铜催化的叠氮氰甲基化反应，通过形成 $\mathrm{C}-\mathrm{N}$ 键 和 $\mathrm{C}-\mathrm{C}$ 键生成 $\gamma$-叠氮烷基腈. 这一目标产物又很容易 转化为 1,4 -二胺、 $\gamma$-氨基腈、 $\gamma$-叠氮酯和 $\gamma$-内酰胺等在有 机合成和药物化学中有用的化合物(Scheme 51).

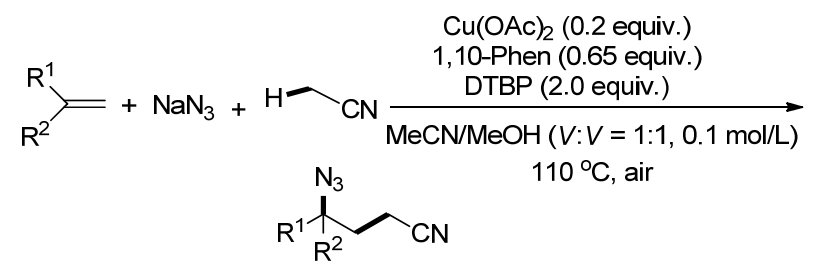

图式 51 铜催化烯烃的三组分碳叠氮化反应

Scheme 51 Cu-catalyzed three-component carboazidation of alkenes 


\subsection{4 烯烃的叠氮氯化反应}

2014 年, Wang 课题组 ${ }^{[64]}$ 报道了铜催化芳基烯烃的 分子间叠氮氰化反应, 以优良的产率得到了一系列的 3叠氮-2-芳基丙腈类化合物, 为 3-氨基-2-芳基丙酸的合 成提供了一种潜在的策略(Scheme 52).

$$
\mathrm{Ar} \curvearrowright+\mathrm{TMSN}_{3}+\mathrm{TMSCN} \frac{\mathrm{Cu}(\mathrm{TFA})_{2}, \mathrm{Phl}(\mathrm{OAc})_{2}}{\mathrm{MeOH} \text {, r.t. }} \stackrel{\mathrm{CN}}{\longrightarrow} \mathrm{N}_{3}
$$

图式 52 铜催化芳基烯烃的分子间叠氮氰化反应

Scheme $52 \mathrm{Cu}$-catalyzed intermolecular azidocyanation of aryl alkenes

2017 年, Lin 与 Liu 课题组 ${ }^{[65}$ 报道了通过自由基历 程的铜催化烯烃的分子间不对称氨氰基化反应和叠氮 氧化反应, 这一过程中芐基自由基被手性双噁唑啉配 体 $/ \mathrm{Cu}(\mathrm{II})$ 氧化物的络合物选择性地捕获, 高效地生成各 种对映体富集的 $\beta$-氨基/叠氮化烷基腈. 而 $\beta$-叠氮化烷 基腈可以转化成一系列具有价值的光学活性胺基建筑 材料和生物活性化合物(Scheme 53).

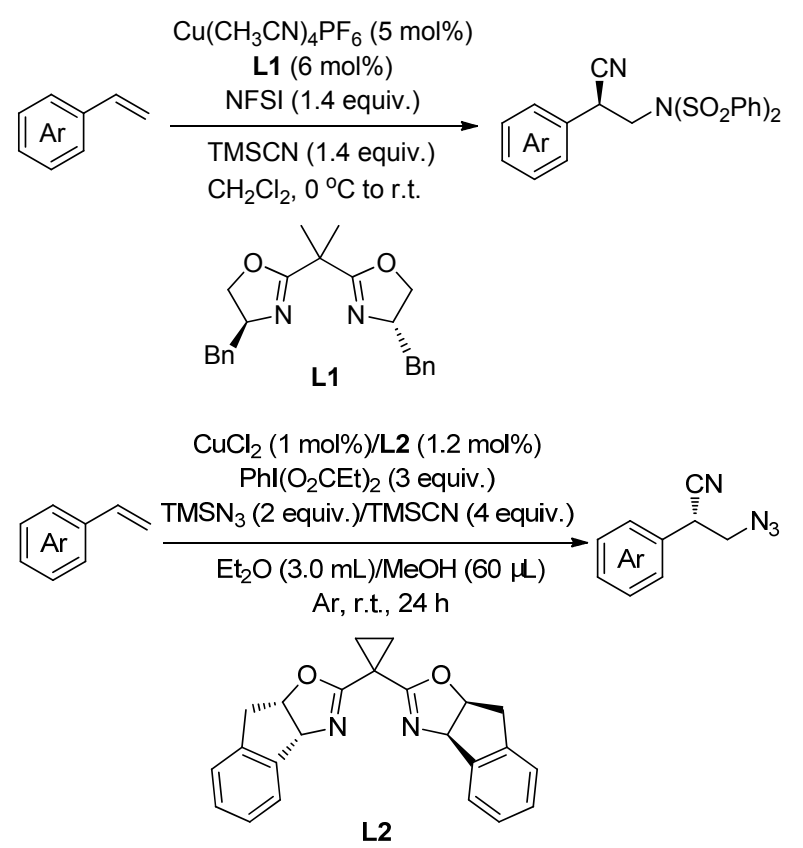

图式 53 铜催化烯烃的分子间不对称氨氰基化反应和叠氮氰 化反应

Scheme 53 Cu-catalyzed intermolecular amino- and azidocyanation of alkenes

\section{5 烯烃的其它双官能团化反应}

\subsection{1 烯烃的二酯化反应}

烯烃的双官能团化反应，包括氨氧化反应、二氨化 反应、氨卤化反应等已经得到了广泛的发展, 相比之下, 共轭烯烃的双官能团化反应还没有引起太多的关注. 2016 年, Bao 课题组 ${ }^{[6]}$ 报道了铜催化 1,3-二烯的二酯化 反应, 且反应过程可能有烯丙基自由基参与, 后以优良
的产率生成了烯丙基二酯衍生物，这类产物是合成天然 产物的重要中间体(Scheme 54).

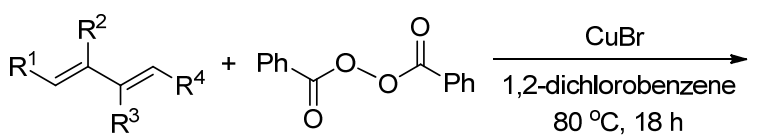

$$
\begin{aligned}
& \underbrace{\mathrm{OBBz}^{2}}_{\mathrm{BzO} \mathrm{R}^{3}}+\underbrace{\mathrm{R}^{4}}_{\mathrm{OBz} \mathrm{R}^{3}}
\end{aligned}
$$

图式 54 铜催化 1,3-二烯的二酯化反应

Scheme 54 Cu-catalyzed diesterification of 1,3-diene

\subsection{2 烯烃的氨基内酯化反应}

2016 年, Wang 课题组 ${ }^{[67]}$ 报道了铜催化不饱和羧酸 的氨基内酯化反应以及类似的分子间烯烃的三组分氨 基氧化反应，反应条件温和，底物范围广泛，通过邻苯 甲酰羟胺促进烯烃的亲电氨化反应, 生成胺基内酯以及 1,2-氨基醇衍生物(Scheme 55).

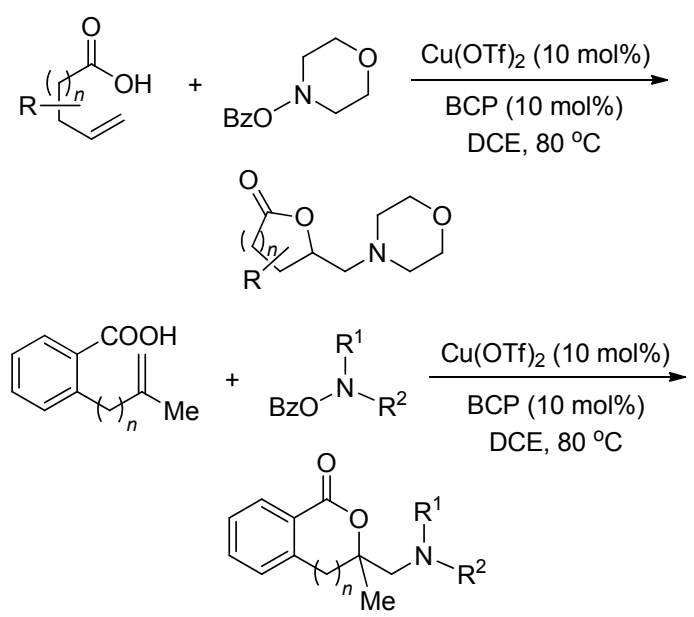

图式 55 铜催化烯烃的氨基内酯化反应

Scheme $55 \mathrm{Cu}$-catalyzed amino lactonization of alkenes

\subsection{3 烯烃的烷氰基环醚化反应}

2016 年, Zhu 课题组 ${ }^{[68]}$ 报道了烯烃的烷氧基环醚化 反应, 铜催化下, 以 $\mathrm{MeCN} / \mathrm{MeOH}$ 为溶剂, 烷基氰作为 烷基来源, 通过形成 $\mathrm{C}-\mathrm{C}$ 键、 $\mathrm{C}-\mathrm{O}$ 键生成 1,3-二氢异 苯并呋喃化合物, 并且可以通过此方法合成抗抑郁的药 物西酞普兰(Scheme 56).

\section{2 其它过渡金属催化的烯烃的双官能团化反应}

继 Warcker 反应被发现之后，过渡金属催化烯烃的 双官能团化反应一直是人们研究的热点, 因其显著的高 效性, 人们对它的关注度从未降低, 新策略不断被提出, 新颖的底物不断被发现着, 各种催化机理的提出、验证, 都在推动这一领域的发展, 而近几年人们对其研究也从 


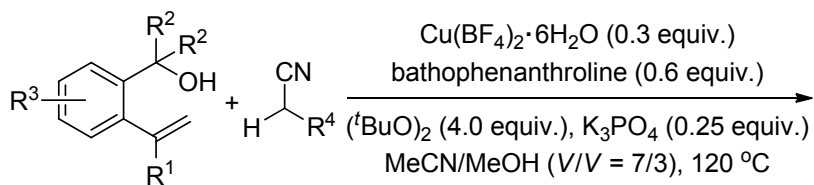<smiles>[R]C(C#N)CC1([R])OC([R])([R])c2cc[R1]([H])cc21</smiles>

图式 56 铜催化烯烃的烷氰基环醚化反应

Scheme $56 \mathrm{Cu}$-catalyzed cyanoalkylative cycloetherification of clkenes

未停断.

\section{1 铁催化烯烃的双官能团化反应}

2010 年, Yoon 课题组 ${ }^{[69]}$ 报道了烯烃分子间的氨羟 基化反应, 反应以 $\mathrm{Fe}(\mathrm{acac})_{3}$ 为催化剂, 其中氧杂吅丙啶 开环既作为氧源又作为氮源, 在乙腈中与烯烃发生 1,2加成反应并以较高的产率生成 2,4-取代的噁唑烷化合 物. 反应具有良好的底物普适性, 可以与各种烷基烯 烃、芳基烯烃、共轭烯烃以及共轭烯炔类化合物很好的 发生反应得到目标产物, 反应所用的铁催化剂不仅价格 便宜且毒性较低, 而且该反应对有机药物的合成具有重 要的应用价值(Scheme 57).

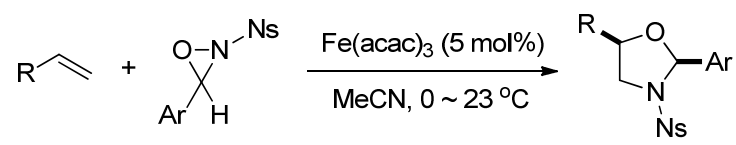

图式 57 铁催化烯烃的分子间氨着基化反应

Scheme 57 Iron-catalyzed interrmolecular oxyamination of alkenes

2013, Xu 课题组 ${ }^{[70]}$ 报道了二价铁催化的烯烃与功 能化着弪胺的分子内氨羟基化反应, 这一高效的分子内反 应以优异的选择性 $(d r>20: 1)$ 合成了具有应用价值的 氨基醇. 反应没有添加其他金属盐或者高价碘来做氧化 剂, 只以 $\mathrm{K}_{4} \mathrm{Fe}(\mathrm{CN})_{6}$ 作为催化剂, 乙腈作为溶剂, 在 $70{ }^{\circ} \mathrm{C}$ 的条件下生成五元环酰胺酯类化合物. 该反应具 有良好的底物普适性, 各种烷基烯烃和芳基烯烃都以中 等及以上的产率得到了相应的产物. 作者认为该反应是 先通过铁与配体形成新的络合物, 之后与氨基络合成新 的中间体，可以发生氨羟基化反应生成五元环化合物， 也可以生成氮杂环丙烷(Scheme 58).

2014 年, 该课题组 ${ }^{[71]}$ 再次报道了铁催化烯烃分子 间的氨氧化反应, 以 $\mathrm{Fe}(\mathrm{OTf})_{2}$ 为催化剂, 稳定的功能化 的差弪胺作为胺化试剂和氧化剂, 这一方法对底物烯烃有 很好的普适性, 包括那些对现有的氨氧化反应不适用的 烯烃, 也可以得到具有区域和立体化学骨架的氨基醇衍

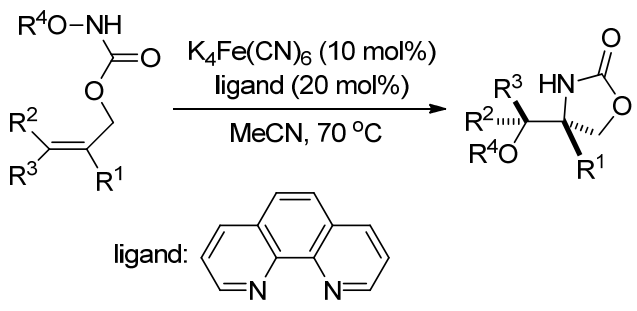

图式 58 铁催化烯烃的分子内氨羟基化反应 Scheme 58 Iron-catalyzed intrarmolecular oxyamination of alkenes

生物(Scheme 59).
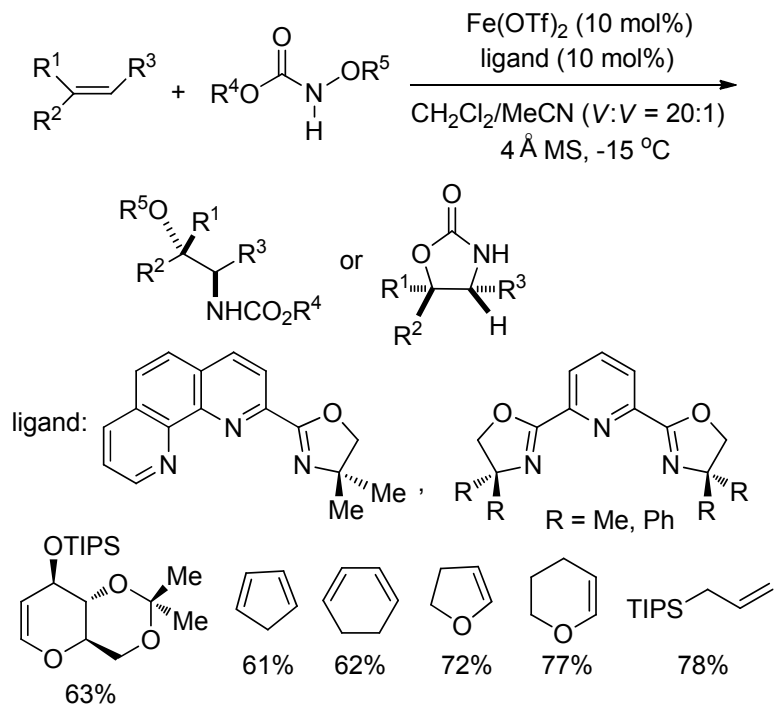

图式 59 铁催化烯烃的分子间氨氧化反应

Scheme 59 Iron-catalyzed interrmolecular aminooxygenation of alkenes

2016 年, $\mathrm{Xu}$ 课题组 ${ }^{[72]}$ 又报道了铁催化的非对映选 择性烯烃的直接二氨化反应, 催化剂和配体与之前相 同，室温反应，且同样具有很好的底物普适性，可以得 到高达 90\%的产率和 $20: 1$ 的 $d r$ 值. 反应历经自由基反 应历程，其中路易斯酸的活化作用对第一次叠氮基团的 迁移是必不可少的，而铁催化剂与叠氮基团的第二次迁 移相关(Scheme 60).

2017 年, Zhang 与 Bao 课题组 ${ }^{[73]}$ 通过一系列反应(自 由基加成、氧化和 Ritter 反应)建立了芳乙烯类的烷基氨 化反应和 $\alpha, \beta$-不饱和酯类的非对映选择性反一烷基氨化 反应，以铁为催化剂，使简单的烯烃以优良的效率合成 了胺类和双取代的 $\beta$-氨基酸类化合物. 而且, 得到的高 非对映选择性 $\beta$-氨基酸化合物可以进一步用于其他的 领域. 此外，这一自由基-极性交叉反应是通过铁催化 剂和双功能的烷基过氧化物来确保进行的. 其中，烷基 二酰基过氧化物可从脂肪酸合成，作为烷基化试剂和内 部氧化剂. 且计算研究表明把腈加成到碳正离子上是非 


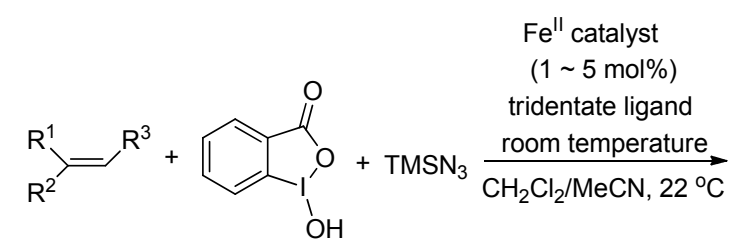

d.r. up to $>20: 1$
yield up to $91 \%$

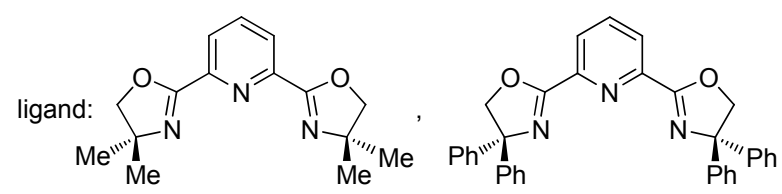

图式 60 铁催化烯烃的非对映选择性二氨化反应

Scheme 60 Iron-catalyzed diastereoselective interrmolecular diamination of alkenes

对应立体选择性的决定步骤(Scheme 61).

$$
\text { 至 }
$$

图式 61 铁催化烯烃的碳氨化反应

Scheme 61 Iron-catalyzed carboamination of olefins

\section{2 铑催化烯烃的双官能团化反应}

2011 年, Buchwald 等 ${ }^{[74]}$ 将具有较大空间位阻的手 性双膦配体应用于铑催化的 $\alpha$-烷基丙烯酸酯的不对称 氢甲酰化反应中, 获得了较高产率及优良对映选择性的 直链醛产物(Scheme 62).

$$
\begin{aligned}
& \mathrm{R}^{1}{ }_{\mathrm{COOR}} \frac{\begin{array}{c}
\mathrm{Rh}(\mathrm{acac})(\mathrm{CO})_{2}(1.0 \mathrm{~mol} \%) \\
\text { ligand }(1.2 \mathrm{~mol} \%)
\end{array}}{\begin{array}{c}
\mathrm{H}_{2} / \mathrm{CO}(\mathrm{V}: \mathrm{V}=5: 1,1.0 \mathrm{MPa}) \\
100^{\circ} \mathrm{C} \text {, dodecane }
\end{array}} \mathrm{R}^{1} \text { }^{2} \mathrm{COOR} \\
& \text { ligand: }
\end{aligned}
$$

图式 62 铑催化下的不对称氢甲酰化反应

Scheme 62 Rhodium-catalyzed asymmettric hydroformylation

2014 年, Bois 课题组 ${ }^{[75]}$ 报道了铑催化烯烃的二氨化
反应，采用一步法串联反应，包括铑催化形成氮杂环丙 烷，随后 $\mathrm{NaI}$ 促进氮杂环丙烷产物的重排以高产率生成 环化磺酰胺. 得到的环化磺酰胺化合物在热水和吡啶中 可以开环生成不同保护基团的二氨产物. 由于环化磺酰 胺产物简单温和的开环方式，使得它具有很好的应用， 如合成一些天然多肽抗生素的氨基酸组分: (土)-enduracididine、(士)-allo-enduracididine (Scheme 63).

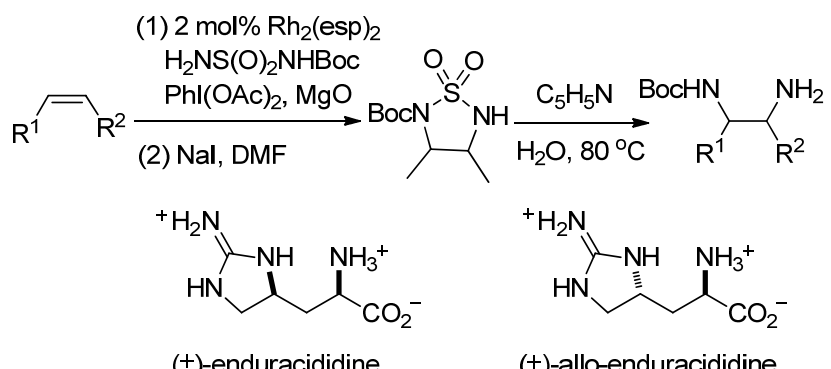

图式 63 铑催化下烯烃的邻位二氨化反应

Scheme 63 Vicinal diamination of alkenes under Rh-catalysis

2015 年, Rovis 课题组 ${ }^{[76]}$ 报道了铑催化下烯烃的双 官能团化反应得到顺式的二取代的芳胺化产物. 反应以 苯氧基邻苯二甲酰亚胺和三价铑为催化剂, 形成了新的 庞大的茂基基团，也因此改变了反应固有的化学选择 性，其中以甲醇作为溶剂也是至关重要的，它使邻苯二 甲酰亚胺基团经历了原位开环。且机械实验表明，羰基 的碱度通过配位饱和使 Rh(III)中间体稳定，从而发生还 原消除而不是环丙基化(Scheme 64).
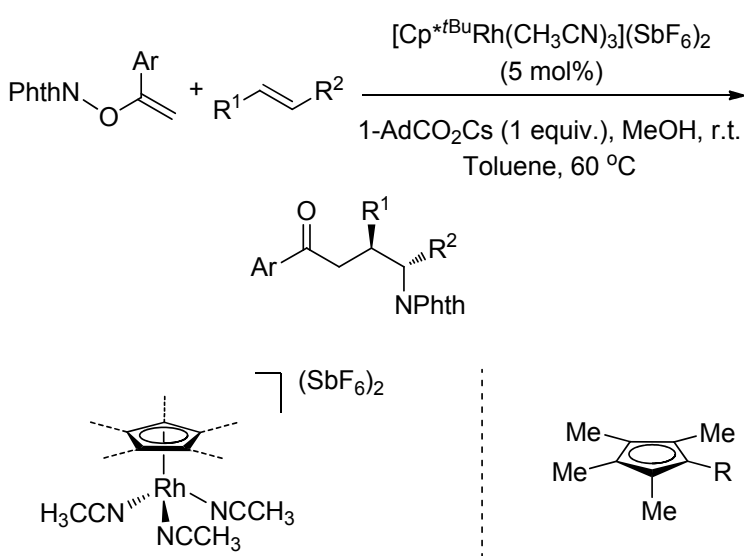

$\left[\mathrm{Cp}^{\mathrm{x}} \mathrm{Rh}\left(\mathrm{CH}_{3} \mathrm{CN}\right)_{3}\right]\left(\mathrm{SbF}_{6}\right)$

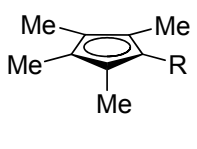

$\mathrm{Cp}{ }^{\mathrm{xtBu}}: \mathrm{R}={ }^{t} \mathrm{Bu}$

图式 64 铑催化烯烃的碳氨化反应

Scheme 64 Rhodium-catalyzed syn-carboamination of alkenes

2016 年, Gandon 课题组 ${ }^{[77]}$ 报道了铑催化的烯烃与 乃春发生的双官能团化反应，以优良的产率生成了氨氧 化产物和二氨化产物. 反应先生成氮杂环丙烷, 然后由 铑与乃春键合以诱导亲核开环反应(Scheme 65). 


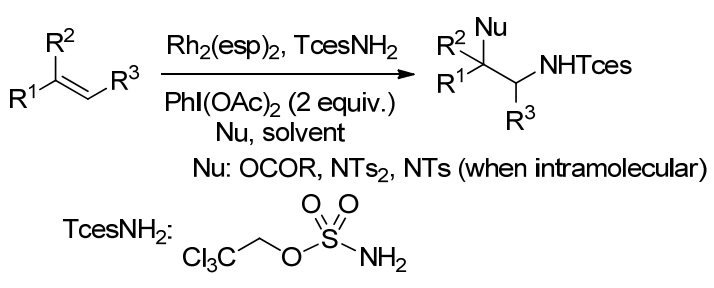

图式 65 铑催化烯烃与氮宾的双官能团化反应

Scheme 65 Rhodium-catalyzed alkene difunctionalization with nitrenes

\section{3 锰催化烯烃的双官能团化反应}

2017 年, Lin 课题组 ${ }^{[78]}$ 报道了锰催化烯烃的电化学 二氯化反应, 该方法操作简单、可持续且可高效的得到 多种邻二氯化合物, 特别是具有氧化活性官能团(如醇、 醛、硫化物和胺)的烯烃, 可被转化成具有高化学选择性 的邻二氯化合物. 这一反应以电为主要能源输入, $\mathrm{H}_{2}$ 和 $\mathrm{Mg}(\mathrm{OAc})_{2}$ 为得到的唯一副产物(Scheme 66).

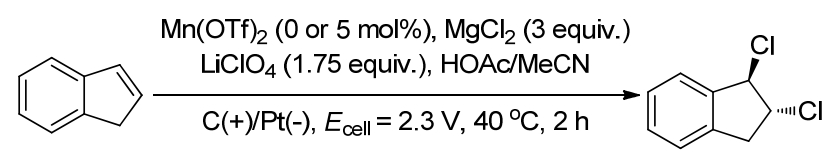

图式 66 电催化烯烃与亲核氯源的自由基二氯化反应 Scheme 66 Electrocatalytic radical dichlorination of alkenes with nucleophilic chlorine sources

同年, Duan 课题组 ${ }^{[79]}$ 通过 $\mathrm{MnI}_{2}$ 催化非功能化烯烃 的分子内碘氨化反应，随后吟丙啶离子与醇或酚类反应 发生的开环反应制备了脯氨醇醚类化合物. 在催化量的 $\mathrm{MnI}_{2}$ 和 2 equiv. $\mathrm{NaI}$ 催化下, 乙醇溶剂中, 不同的 4-烯 -1-氨底物发生分子内氨基烷氧化反应生成产率高达 90\%的 2-(烷氧烷基)吡咯烷产物(Scheme 67).

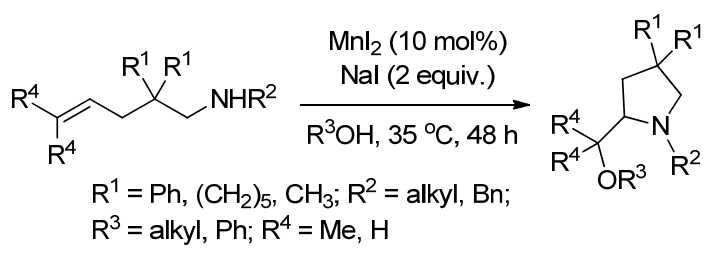

图式 67 非功能化烯烃的分子内氨基烷氧化反应 Scheme 67 Intramolecular amino alkoxylation of unfunctionalized olefins

\section{4 银催化烯烃的双官能团化反应}

2014 年, Yadav 课题组 ${ }^{[80]}$ 报道了温和条件下银催化 的烯烃的分子间氧硫化反应, 反应经历自由基历程, 生 成 $\beta$-酮一砜类化合物. 反应中, 亚硫酸钠被一价银氧化 为亚磺酸基自由基, 之后亚磺酸自由基进攻烯烃形成碳 中心的自由基, 其与氧气进一步形成氧中心自由基, 再 与碳中心自由基反应并脱去氢自由基得到产物. 该反应 室温条件下进行, 以水为溶剂, 反应条件温和, $16 \mathrm{~h}$ 完 成就可以得到高产率的产物(Scheme 68).

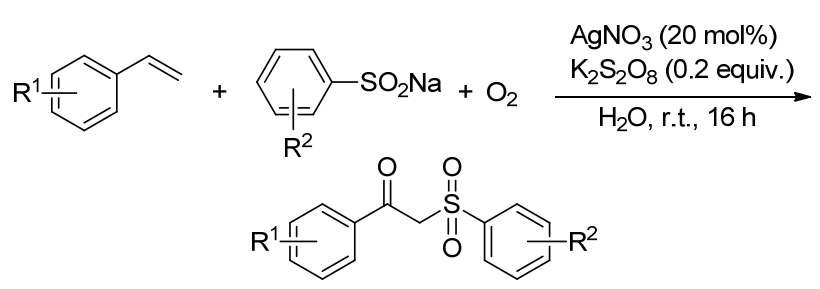

图式 68 银催化的烯烃的分子间氧硫化反应

Scheme $68 \mathrm{AgNO}_{3} / \mathrm{K}_{2} \mathrm{~S}_{2} \mathrm{O}_{8}$ catalyzed aerobic oxysulfonylation of alkenes

2017 年, Tang 课题组 ${ }^{[81]}$ 以三氟甲基芳基磺酸酯 (TFMS)为三氟甲氧基化试剂，报道了银催化烯烃的分 子间不对称溴三氟甲基氧化反应，与其他三氟甲氧基化 试剂相比, TFMS 不仅合成方便, 热稳定且反应活性好, 能以优良的产率及选择性得到溴-三氟甲氧基化目标产 物. 另外, 此反应操作简单, 反应条件温和, 底物范围 广，官能团兼容性好，可以实现克级规模的制备，还可 以用于复杂天然产物或天然产物类似物中双键的衍生 化，在有机合成及药物修饰改造中具有很大的应用价值 (Scheme 69).

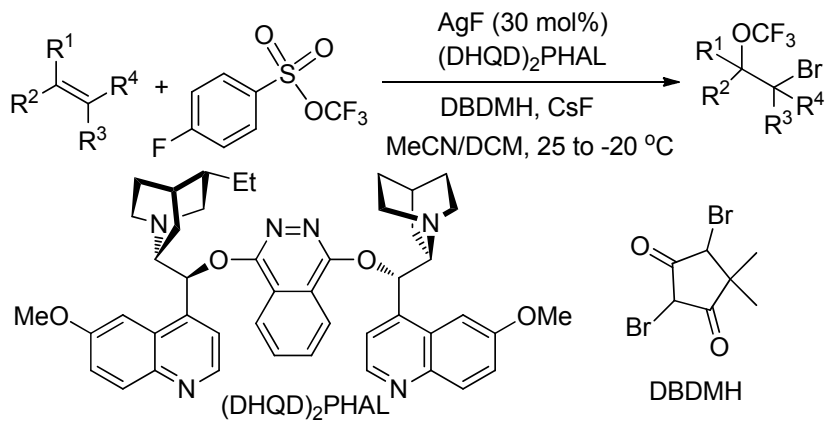

图式 69 银催化的烯烃的分子间不对称澳三氟甲基氧化反应 Scheme 69 Asymmetric silver-catalysed intermolecular bromotrifluoromethoxylation of alkenes

\section{5 铱催化烯烃的双官能团化反应}

2013 年, Greaney 课题组 ${ }^{[82]}$ 报道了一个光催化的三 组分串联反应, 以 $\operatorname{Ir}(\mathrm{ppy})_{3}$ 为催化剂, 苯乙烯、芳基化合 物及异原子的亲核试剂(如醇、水或腈)反生碳氧/氨化反 应，其中四氟硼酸为碳源，醇为氧源．该反应不仅反应 条件温和, 且底物普适性很好, 无论一级醇还是二级醇 都可以得到相对应的产物(Scheme 70).

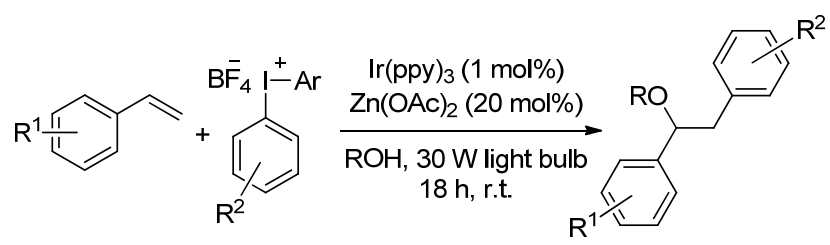

图式 70 光催化烯烃的碳氧/氨化反应

Scheme 70 Oxyarylation and aminoarylation of styrenes using photoredox catalysis 
2016 年, Cavallo 课题组 ${ }^{[83]}$ 报道了氮杂环铱复合物 作用下未活化烯烃的氢氨化反应, 在这一催化体系下得 到了具有极好的对映选择性的吡咯烷化合物(Scheme 71).

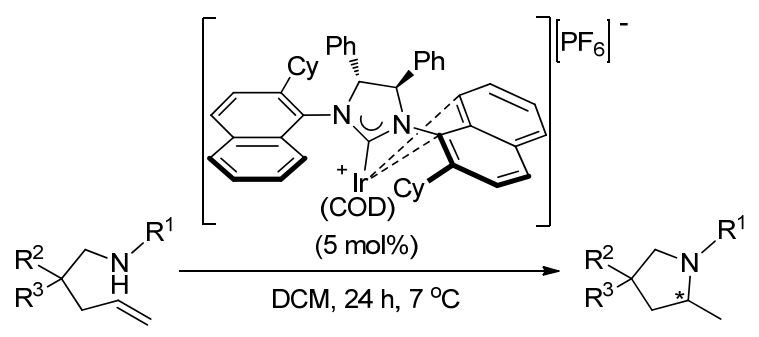

图式 71 氮杂环铱复合物作用下未活化烯烃的氢氨化反应 Scheme 71 NHC-iridium(I) complexes catalyzed intramolecular hydroamination of unactivated aminoalkenes

2018 年, Rovis 课题组 ${ }^{[84]}$ 报道了温和条件下铱催化 烯烃的二氨化反应，其区域选择性由溶剂和铱络合物决 定，且其反应可以经过两种不同的反应途径，分别生成 五元环和六元环化合物(Scheme 72).<smiles>[R20]CC1NC(=O)CC1[R]</smiles>

图式 72 铱催化烯基酰胺的二氨化反应

Scheme 72 Iridium(III)-catalyzed diamination of alkenyl amides

\section{6 钯催化烯烃的双官能团化反应}

2013 年, Liu 课题组 ${ }^{[85}$ 报道了分子间烯烃的氨基乙 酰氧基化反应, 以 $\mathrm{PdCl}_{2}(\mathrm{NCPh})_{2}$ 作为钯催化剂, 邻苯二 甲酰亚胺作为氮源，醋酸碘苯作为氧源，同时该课题组 比较了醋酸碘苯和氧气分别作为氧化剂时反应的不同, 发现醋酸碘苯在改变反应胺钯化步骤的立体化学结构 时起决定性的作用. 作者推测反应是先发生 trans-或 $c i s$-胺钯化作用得到 $\operatorname{Pd}(\mathrm{II})$ 中间体, 之后醋酸碘苯将其氧 化为 $\operatorname{Pd}(\mathrm{IV})$ 中间体, 最后构型反转还原消除生成产物. 且对于末端烯烃或者非末端烯烃反应都可以很好地发 生，该反应具有很好的底物适用范围(Scheme 73).

2014 年, Studer 课题组 ${ }^{[86]}$ 报道了温和条件下钯催化 的苯并呋喃类化合物的 1,2-碳氧化反应，反应具有高度 的非对映选择性，反应以便宜且易制备的苯并呋喃和芳 基硼酸、羒酸为原料, 以 2,2,6,6-四甲基哌啶-1-氧化物 (TEMPO)为氧化剂, $\mathrm{Pd}(\mathrm{OAc})_{2}$ 作为催化剂, 底物羧酸作

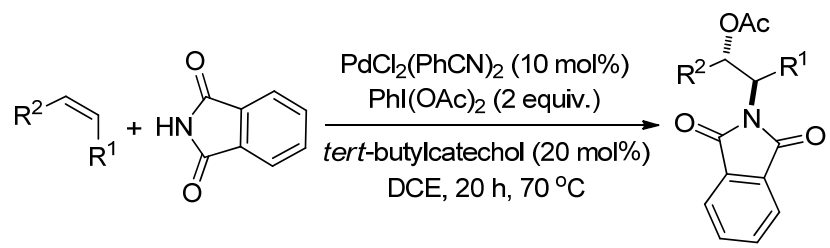

图式 73 钯催化分子间烯烃的氨基乙酰氧基化反应 Scheme 73 Palladium catalyzed intermolecular aminoacetoxylation of alkenes

为溶剂，常温下就可以得到高产率及高非对映选择性、 完整的区域选择性的 2-烷基-2-芳基-3-酯基-2,3-二氢苯 并呋喃框架的目标产物. 这一反应对天然产物及药物的 合成具有很大的潜在应用价值(Scheme 74).

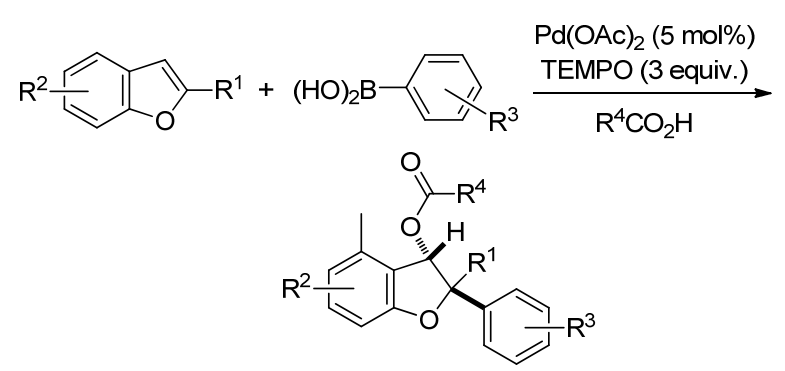

图式 74 钯催化苯并呋喃类化合物的 1,2-碳氧化反应 Scheme 74 Palladium-catalyzed oxyarylation of benzo $[b]$-furans

随后, Studer 课题组 ${ }^{[87]}$ 又报道了 2-烷基吲哚的 1,2碳氧化反应，同样以 $\mathrm{Pd}(\mathrm{OAc})_{2}$ 作为催化剂, TEMPO 为 温和的氧化剂, 使 2-取代的吲哚与商业可用的硼酸发生 高度非对映选择性的碳氧化反应，生成吲哚啉类化合 物. 该反应在室温条件下 $4 \mathrm{~h}$ 就可以完成, 产率也较高, 且酯基可以进一步水解为相应的醇，这也为此反应的进 一步应用提供了条件(Scheme 75).

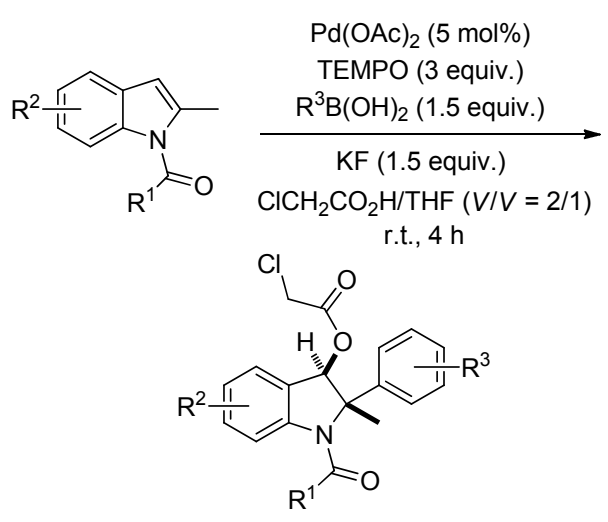

图式 75 钯催化 2-烷基吲哚的 1,2-碳氧化反应 Scheme 75 Palladium-catalyzed diastereoselective oxyarylation of 2-alkylindoles

2016 年, Liu 课题组 ${ }^{[88]}$ 以氧化稳定的吡啶噁唑啉为 手性配体，钯作为催化剂，NFSI 为氮源，发生的烯烃的 
分子间氢胺化反应, 其中修饰的手性配体对迁移插入步 骤有很好的对映选择性控制, 最终以优良的区域选择性 和对映选择性生成各种芐基酰胺类化合物(Scheme 76).

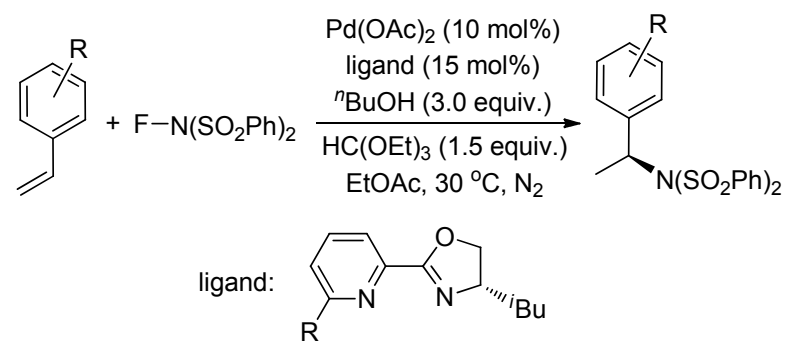

图式 76 烯烃的分子间不对称氢胺化反应

Scheme 76 Intermolecular enantioselective hydroamination of styenes

2017 年, Cheng 课题组 ${ }^{[89]}$ 报道了钯催化的未活化烯 烃与便宜易得的碘代全氟烷烃的芳基全氟烷基化反应, 得到了各种有价值的全氟烷烃化杂环产物. 其中芳基底 物对亲电子取代基有很好的容忍性, 而且使这一方法成 为烯烃双官能团化中极化或自由基引发的芳香环形成 的辅助工具. 此反应以较高的区域选择性得到了各种全 氟烷基化杂环衍生物, 反应条件温和, 且具有很好的底 物普适性(Scheme 77).

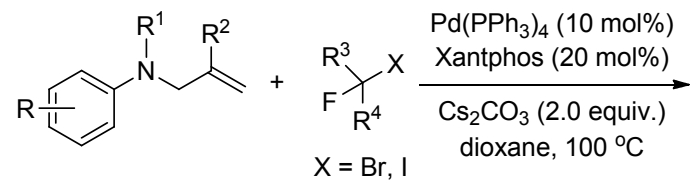<smiles>[R]C=C1c2ccccc2N([R])CC1([R])CC([R])([R])F</smiles>

图式 77 通过钯催化未活化烯烃的芳基全氟烷基化反应合成 杂环化合物

Scheme 77 Pd-Catalyzed arylperfluoroalkylation of unactivated olefins for the synthesis of heterocycles

同年, Shao 课题组 ${ }^{[90]}$ 通过使简单易得的烯烃发生氧 化芳基乙酰氧基化反应合成了吲哚和吲哚啉衍生物, 以 吡咯酰胺为导向基, 肉桂基苯胺通过直接的氧化芳基乙 酰氧基化反应得到中等到良好产率的吲哚, 而 2-甲基取 代的肉桂基苯胺通过连续的氧化芳基乙酰氧基化、水 解、氧化等步骤得到了高产率的吲哚啉衍生物(Scheme 78).

2018 年, Liu 课题组 ${ }^{[91]}$ 报道了钯催化未活化烯烃的 不对称 6-endo 氨基乙酰氧基化反应, 在温和的反应条件 下，利用新型的吡啶噁唑啉配体使得反应最终以极好的 区域选择性和对映选择性得到了手性的 $\beta$-乙酰氧基哌 啶产物. 作者提出, 在吡啶噁唑啉配体的 C-6 位置引入 一个大基团对提高钯催化剂的反应活性以及乙酰氧基

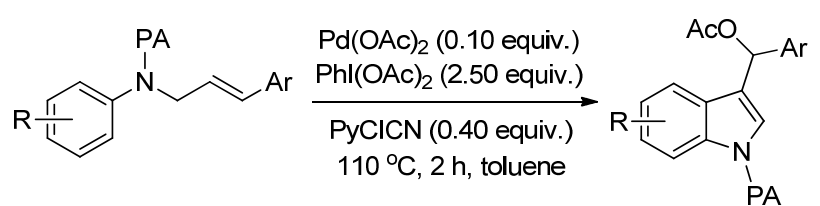

(1) $\mathrm{Pd}(\mathrm{OAc})_{2}$ (0.10 equiv.) $\mathrm{Phl}(\mathrm{OAc})_{2}$ (2.50 equiv.)

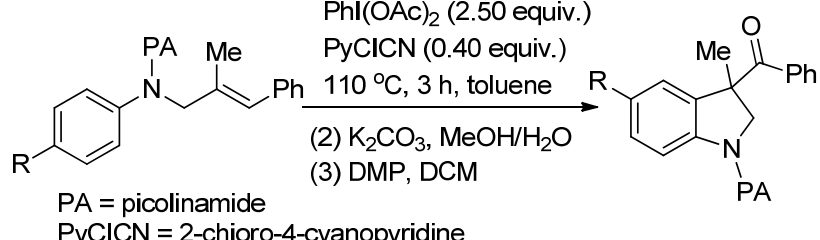

图式 78 钯催化烯烃的氧化芳基乙酰氧基化反应 Scheme 78 Palladium-catalyzed oxidative arylacetoxylation of alkenes

哌啶产物的对映选择性都至关重要(Scheme 79).

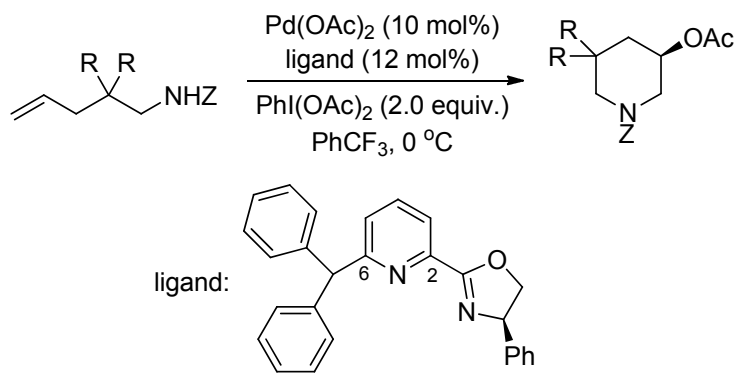

图式 79 钯催化烯烃的氨基乙酰氧基化反应

Scheme 79 Palladium-catalyzed aminoacetoxylation of alkenes

\section{7 硒催化烯烃的二氯化反应}

对于烯烃的双卤化反应，其产物一般都是反式产 物, 即便得到顺式产物, 产率也是很低, 因此关于烯烃 顺式双卤化加成反应的研究就很少. 2015 年, Denmark 课题组 ${ }^{[22]}$ 首次报道了二苯基二硒催化的脂肪系烃的顺 式二氯化反应，该反应具有广泛的底物普适性，不饱和 酯烯烃、环烷烯烃、反式烯烃、顺式烯烃以及丙烯醇都 可以反应，得到 $40 \% \sim 90 \%$ 的产率， $d r$ 值最高达到 99：

1, 作者也推测了该反应的机理(Scheme 80).

\section{3 非金属催化的烯烃的双官能团化反应}

对于烯烃的双官能团化反应，过渡金属由于其价格 昂贵、反应条件要求严格、有反应残留的特点影响了它 的应用范围，而非金属试剂一般毒性较低且便宜易得， 一般符合绿色化学的要求, 因此发展非金属条件下发生 的双官能团化也尤为重要.

\section{1 有机催化的烯烃的双官能团化反应}

2015 年, Tan 和 Liu 课题组 ${ }^{[93]}$ 首次研究出用高对映 选择性的布朗斯特酸催化烯烃的氢胺化反应，在温和的 反应条件下来获得高产率、高对映选择性的 $\alpha$-三取代碳 

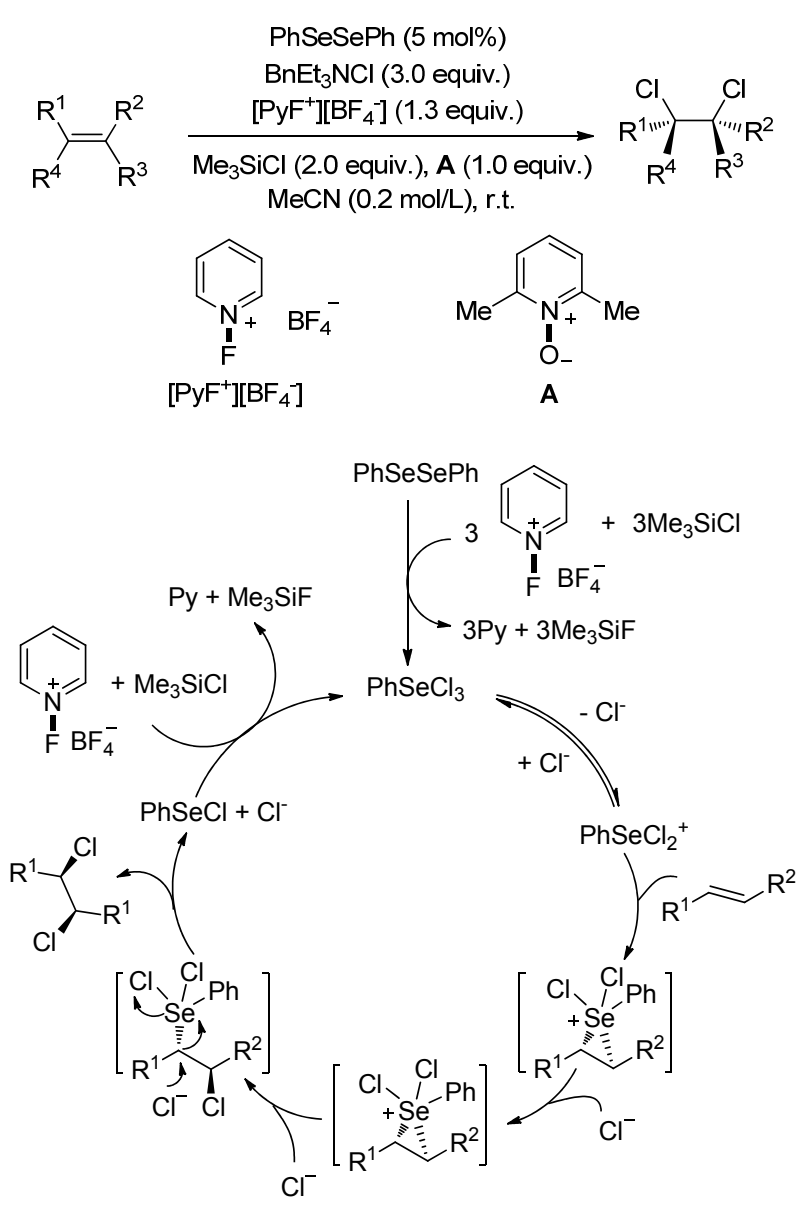

图式 80 硒催化烯烃的顺式二氯化加成可能反应机理 Scheme 80 Proposed catalytic cycle for the selenium-catalyzed syn-dichlorination of alkenes

立体中心的吡咯烷衍生物. 这一方法的特性是通过多氢 键与布朗斯特酸及双键合作，使硫脲基团同时作为活化 集团和导向集团. 而手性合成中间体和有机合成中广泛 存在的重要结构的简单构建, 突出了该方法的实用性 (Scheme 81).

2016 年, Liu 课题组 ${ }^{[94]}$ 报道了在有机碱催化下, 通 过高效化学选择性完成的未活化烯烃与 Togni's 试剂的 芳基三氟甲基化及氧三氟甲基化反应. 该反应通过改变 有机碱催化剂和溶剂来完成化学选择性的转换. 并且作 者通过机理研究表明, 在 DMSO 溶剂中发生的芳基三 氟甲基化反应经历的是自由基环化历程, 而在 DCE 溶 剂中的氧三氟甲基化反应则经历碳正离子历程(Scheme $82)$.

2018 年, List 课题组 ${ }^{[95]}$ 报道了一种手性强布朗斯特 酸催化的烯烃的分子内不对称氢烷氧化反应. 该方法可 以快速获得生物活性的 1,1-二取代四氢呋喃, 包括 (一)-Boivinianin A, 反应操作简单, 可转化多种烯烃, 且具有很好的收率和对映选择性(Scheme 83).

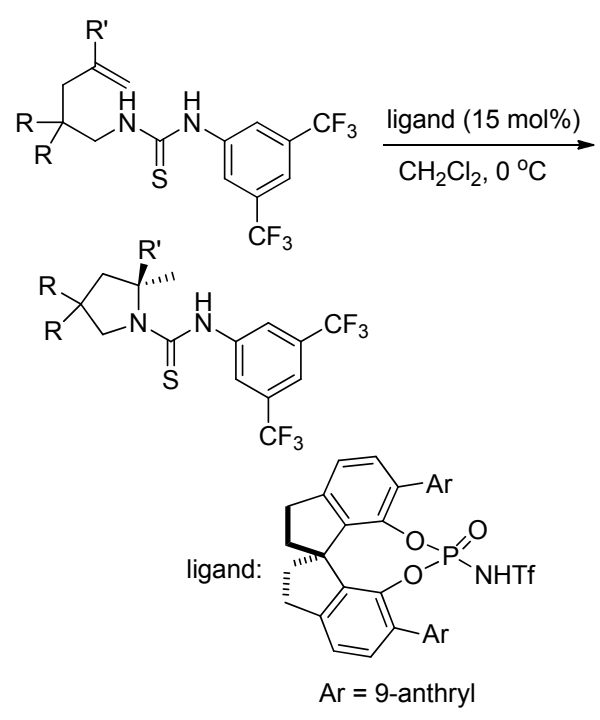

图式 81 布朗斯特酸催化烯烃的氢胺化反应 Scheme 81 Brønsted acid catalyzed asymmetric hydroamination of alkenes

\section{2 其它非金属催化的烯烃的双官能团化反应}

2013 年, Lei 课题组 ${ }^{[96]}$ 报道了无金属催化的条件下 分子间烯烃的氧磺酰化反应，该反应没有添加任何的引 发剂, 实现了亚磺酸的二氧活化, 这一转变可持续且环 保. 这一反应有很好的官能团容忍性，反应条件温和， 以吡啶作为碱, 三苯基膦作为添加剂, 氯仿为溶剂, $40{ }^{\circ} \mathrm{C}$ 的条件下反应 $24 \mathrm{~h}$ 就能得到高产率的目标产物. 作者认为反应过程中, 吡啶首先与芳基亚磺酸作用生成 亚磺酸负离子, 之后在氧气的氧化作用下转化为亚磺酸 自由基，而自由基进一步进攻烯烃形成自由基中间体， 而中间体与氧气作用形成过氧基中间体，最后与吡啶结 合的氢形成过氧酸, 并在酸性的环境中脱去水得到最终 产物(Scheme 84).

2014 年, Chiba 课题组 ${ }^{[97]}$ 通过高价碘试剂 $\left(\mathrm{PhI}(\mathrm{OCOR})_{2} 、 \mathrm{PhI}\left(\mathrm{NMs}_{2}\right)_{2}\right)$ 催化使含脒基的烯烃发生非 对映选择性的氨氧化反应与二氨化反应，而这一反应可 以得到各种用于医药、材料、催化应用的多胺化合物 (Scheme 85).

同年, Hong 课题组 ${ }^{[98]}$ 报道了高价碘试剂催化的烯 烃的二氨化反应, 室温下生成 3-氨基二氢吲哚. 该反应 利用富电子和缺电子(芳基磺酰胺)氮源的组合, 在胺没 有预激活或保护的情况下, 发生烯烃的二氨化反应. 反 应操作简单, 无金属参与, 具有广泛的官能团兼容性 (Scheme 86).

随后, Hong 课题组 ${ }^{[99]}$ 又报道了在高价碘试剂 $\mathrm{PhI}(\mathrm{OAc})_{2}$ 、碘负离子作用下羟基苯乙烯与富电子的二氨 化反应，以双取代的氨与邻或对-羟基苯乙烯反应，反 应具有很好的普适性和官能团兼容性(Scheme 87). 

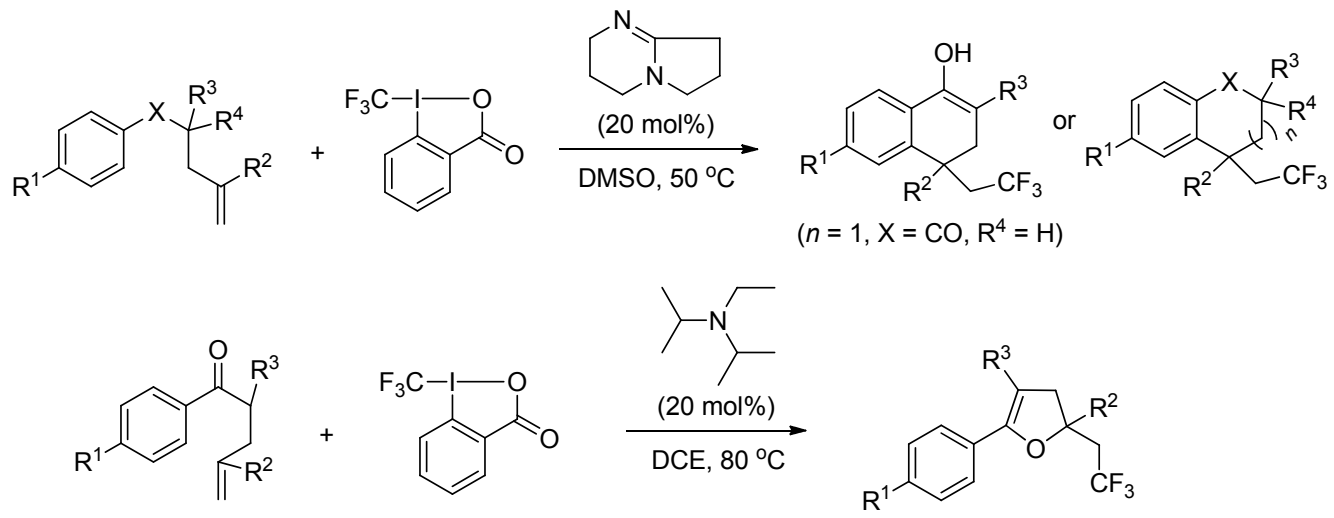<smiles>C=C(C)CC(C(=O)c1ccccc1)C(=O)c1ccccc1</smiles>

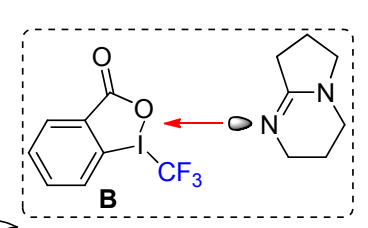<smiles>CC1(CC(F)(F)F)CC(C(=O)c2ccccc2)C(c2ccccc2)O1</smiles>

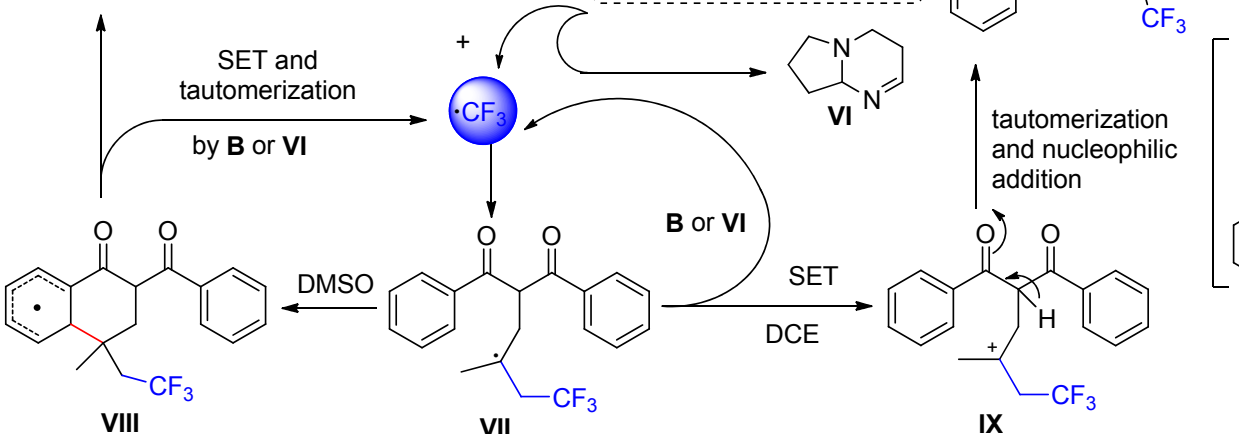<smiles>CC(CC(=O)c1ccccc1)(CC(O)c1ccccc1)CC(F)(F)F</smiles>

图式 82 未活化烯烃的芳基三氟甲基化和氧三氟甲基化反应

Scheme 82 Carbotrifluoromethylation and oxytrifluoromethylation of unactivated alkenes<smiles>[R]C(=C)[Y16](=N)C([R])([R])CO</smiles>

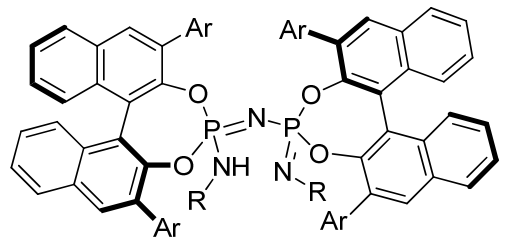

$(S, S)-$ L3

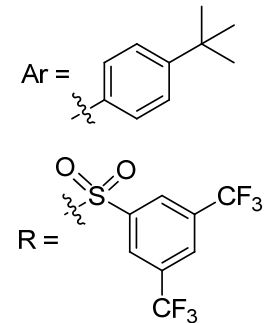

图式 83 烯烃的分子内不对称氢烷氧化反应 Scheme 83 Catalytic asymmetric intramolecular hydroalkoxylation of unbiased olefins

$$
\text { 等 }
$$

图式 84 分子间烯烃的氧磺酰化反应

Scheme 84 Intermolecular oxysulfonylation of alkenes
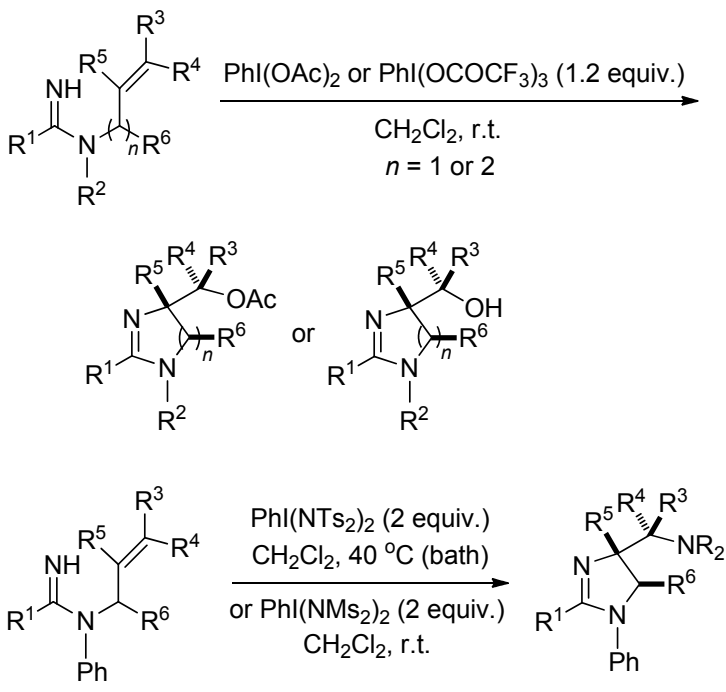

$\mathrm{R}=\mathrm{Ts}, \mathrm{Ms}$

图式 85 高价碘试剂催化烯烃的非对映选择性的氨氧化反应 与二氨化反应

Scheme 85 Diastereoselective amino oxygenation and diamination of alkenes by hypervalent iodine(III) reagents 


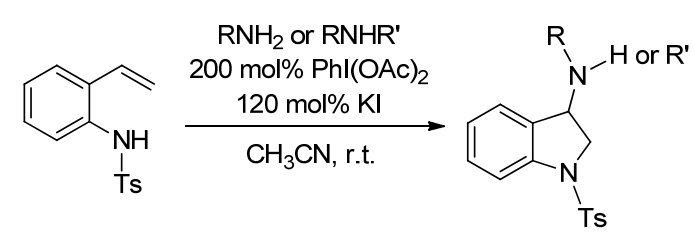

图式 86 高价碘试剂催化的烯烃的二氨化反应 Scheme 86 Hypervalent iodine(III) reagents promoted diamination of alkenes

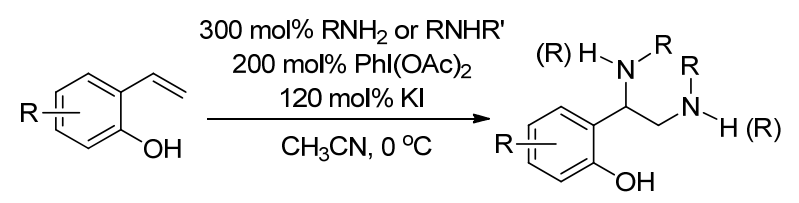

图式 87 羟基苯乙烯与富电子的二氨化反应

Scheme 87 Hydroxy styrenes with electron-rich amines

2015 年, Xia 课题组 ${ }^{[100]}$ 报道了无金属条件下烯烃的 氧叠氮化反应, 以 $N$-羟基邻苯二甲酰亚胺(NHPI)作为 氧自由基的前体, $\mathrm{TMSN}_{3}$ 作为叠氮源, $\mathrm{PhI}(\mathrm{OAc})_{2}$ 为氧化 剂. 首先, NHPI 在氧化剂作用下产生邻苯二甲酰亚胺 氮一氧(PINO)自由基, PINO 与烯烃反应产生的自由基又 再次被 $\mathrm{PhI}(\mathrm{OAc})_{2}$ 氧化为阳离子, 然后叠氮负离子进攻 生成叠氮产物, 且具有良好的官能团兼容性(Scheme 88).

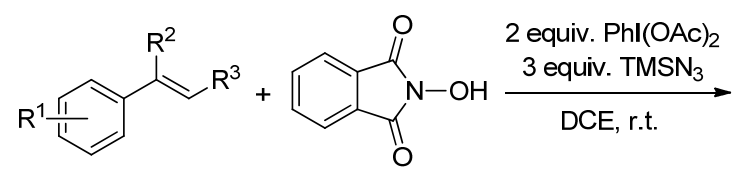<smiles>[R]C(ON1C(=O)c2ccccc2C1=O)C([R])(N)c1cc[R1]:[R]n1</smiles>

图式 88 无金属条件下烯烃的氧叠氮化反应 Scheme 88 Metal-free three-component oxyazidation of alkenes

同年, Cheng 课题组 ${ }^{[101]}$ 报道了室温条件下三氟甲磺 酸催化的烯烃的氢胺化反应. 因 2,2,2-三氟乙基氨基磺 酸盐在有机溶剂及水中都有很好的溶解性, 该反应选择 其为氮源, 便于转化与提纯. 此反应条件下, 底物官能 团兼容性良好, 且以优良的产率得到目标胺化合物 (Scheme 89).

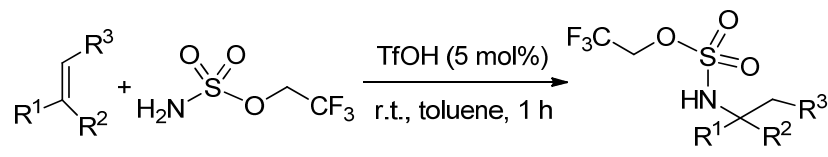

图式 89 三氟甲磺酸催化的分子间烯烃的氢胺化反应 Scheme 89 Intermolecular hydroamination of unfunctionalized alkenes under trifluoromethanesulfonic acid catalysis
这一年, Zhou 课题组 ${ }^{[102]}$ 报道了芳基烯烃的分子间 氧硫化反应，反应条件温和，以 $N, N$-二甲基甲酰胺为溶 剂, 使烯烃与芳基硫酚在 $40{ }^{\circ} \mathrm{C}$ 的条件下反应，以中等 产率得到氧硫化产物. 该反应操作简单, 不需要其它的 添加剂或氧化剂, 为 $\beta$-差欮基硫醚化合物的合成提供了一 种新的合成方法. 得到的 $\beta$-差弪基硫醚化合物可用于药物 和有机合成, 也可以转化为其它功能化合物 (Scheme $90)$.

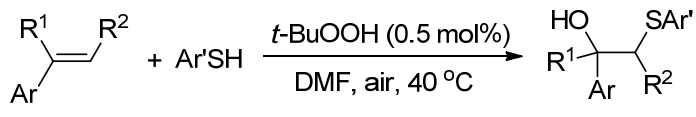

图式 90 芳基烯烃的分之间氧硫化反应

Scheme 90 Intermolecular hydroxysulfurization of styrenes

在这一年, Tan 和 Liu 课题组 ${ }^{[103]}$ 为烯烃的高选择性 1,6-双官能团化反应开发了一种新颖的、简便的非金属 自由基串联方法, 通过 $\mathrm{C}-\mathrm{CF}_{3}$ 的形成、 $1,5-\mathrm{H}$ 迁移及远 程 $\mathrm{sp}^{3}-\mathrm{C}-\mathrm{H}$ 键官能团化这一串联过程得到有价值的三 氟甲基化 $\alpha$-羟基羰基化合物. 另外，也为未活化烯烃的 分子间区域选择性氧三氟甲基化提供了新策略. 其中, Togni's 试剂同时作为 $\mathrm{CF}_{3}$ 源和氧化剂. 值得注意的是, 这一新的自由基反应不仅在非金属条件下进行，而且操 作简单、条件非常温和(Scheme 91).

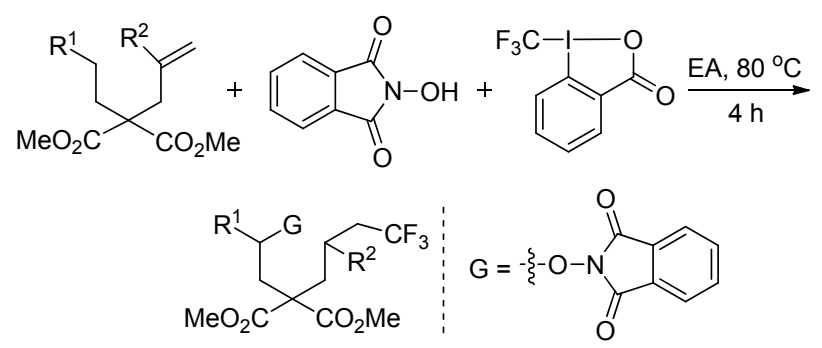

图式 91 烯烃的自由基三氟甲基化反应

Scheme 91 Radical trifluoromethylation of alkenes

2016 年, Kuhakarn 课题组 ${ }^{[104]}$ 报道了苯乙烯衍生物 的硝化肜化反应，亚硝酸特丁酯作为反应试剂，在 DMSO 溶剂中，以简便快捷的方式合成了 $\alpha$-硝基肟化合 物，反应条件温和、操作简单、产率优良、无金属试剂 且溶剂环保(Scheme 92).

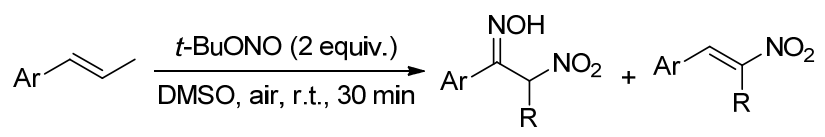

图 92 苯乙烯衍生物与亚硝酸特丁酯的硝化肜化反应 Scheme 92 Nitration-oximization of styrene derivatives with tert-butyl nitrite

2017 年, Dolbier 课题组 ${ }^{[105]}$ 首次报道了光催化的未 活化烯烃的氟烷基芳基化反应，反应条件温和，经过自 由基历程以较好的产率得到了二氟甲基取代的四氢化 
萗衍生物(Scheme 93).

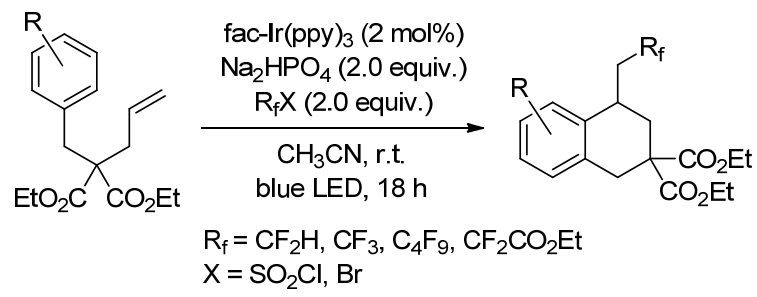

图式 93 光催化的未活化烯烃的氟烷基芳基化反应 Scheme 93 Photoredox catalyzed intramolecular fluoroalkylarylation of unactivated alkenes

同年, $\mathrm{Li}$ 课题组 ${ }^{[106]}$ 报道了 2,4,6-三甲基吡啶催化的 未活化烯烃的三氟甲基炔基化反应, 以 Togni's 试剂为 $\mathrm{CF}_{3}$ 源, 在非金属的条件下与炔基砜类反应生成 $\beta$-三氟 甲基化炔类化合物，反应底物范围广，官能团兼容性好， 且反应提出了非链式自由基历程(Scheme 94).

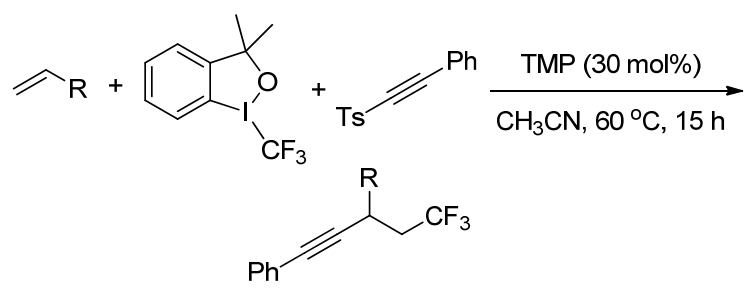

图式 94 未活化烯烃的自由基三氟甲基炔基化反应 Scheme 94 Catalytic radical trifluoromethylalkynylation of unactivated alkenes

随后, Muñiz 课题组 ${ }^{[107]}$ 在分子间反应的控制下, 首 次实现了碘(I/III)催化的苯乙烯的对映选择性二氨化反 应. 该反应以手性改造的的芳基碘(I)为催化剂，间氯过 氧苯甲酸为末端氧化剂, 且环境友好的组合溶剂不仅增 加了该工艺的吸引力, 而且减缓了背景反应的速率. 得 到了 $91 \% \sim 98 \%$ 的 $e e$ 值. 该反应为邻二胺基化合物的合 成提供了重要的方法, 为药物研究提供了重要的实体, 且手性芳酰胆碱催化剂的方法将作为相关转化的指南 (Scheme 95).

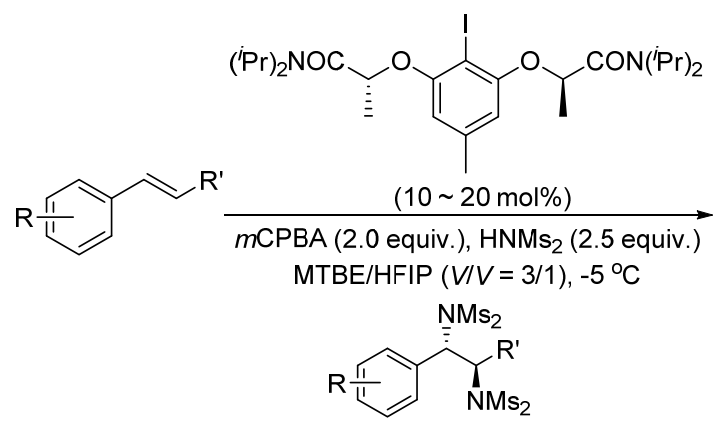

图式 95 苯乙烯的不对称二氨化反应

Scheme 95 Catalytic asymmetric diamination of styrenes

\section{4 结论与展望}

作为一类重要的有机化学反应，烯烃的双官能团化 反应不仅可以经济有效地一步合成多位点反应产物，而 且反应效率高, 为构建化学结构的多样性提供了更多的 方法. 近十几年来, 烯烃的双官能团化反应迅速发展, 从各种过渡金属催化(如 $\mathrm{Cu} 、 \mathrm{Fe} 、 \mathrm{Pd} 、 \mathrm{Rh} 、 \mathrm{Ir} 、 \mathrm{Mn} 、 \mathrm{Ag}$ 等)到非金属催化的双官能团化反应都被广泛的报道, 且得到了非常广泛的应用. 烯烃作为一种非常普遍的前 手性基团，通过双官能团化反应，可以一步合成含有生 物活性或药物活性的产物. 烯烃的双官能团化反应为一 些有机催化剂或手性配体的发展提供了更好的方法，而 且可以进一步合成高度复杂的化合物. 随着研究的进 展，也发展了一系列符合绿色化学要求的非金属催化的 双官能团化反应.

随着研究的深入, 烯烃的双官能团化反应仍面临很 多问题和挑战. 对于不含附属功能基底物的烯烃，大多 数条件下双官能团化反应很难发生. 对于金属催化烯烃 的双官能团化反应，催化剂的回收及循环利用问题仍需 要更多的研究. 随着人们对绿色化学越来越多的关注, 未来烯烃的双官能团化反应也必将努力响应绿色化学 的号召. 将是该类反应研究的核心内容之一, 并将继续 是人们关注的热点. 目前, 烯烃的双官能团化反应还缺 之成体系的理论指导, 相关的动力学研究以及对反应历 程的理解方面还有待进一步的深入研究. 因此, 未来烯 烃的双官能团化反应将会有更进一步的发展，而它在有 机领域也将会有更加重要、更加广泛的应用.

\section{References}

[1] (a) Gaich, T.; Baran, P. S. J. Org. Chem. 2010, 75, 4657. (b) Wender, P. A. Chem. Rev. 1996, 96, 1.

[2] (a) Xu, L.; Mou, X. Q.; Chen, Z. M.; Wang, S. H. Chem. Commun. 2014, 50, 10676

(b) Beccalli, E. M.; Broggini, G.; Martinelli, M.; Sottocornola, S. Chem. Rev. 2007, 107, 5318.

(c) Jensen, K. H.; Sigman, M. S. Org. Biomol. Chem. 2008, 6, 4083.

(d) Chemler, S. R. Org. Biomol. Chem. 2009, 7, 3009.

(e) Muniz, K. Angew. Chem., Int. Ed. 2009, 48, 9412.

(f) Li, G.; Kotti, S. R. S. S.; Timmons, C. Eur. J. Org. Chem. 2007, 2745.

[3] (a) Zhou, M. B.; Wang, C. Y.; Song, R. J.; Liu, Y.; Wei, W. T.; Li, J. H. Chem. Commun. 2013, 49, 10817.

(b) Mu, X.; Wu, T.; Wang, H. Y. Guo, Y. L.; Liu, G. J. Am. Chem. Soc. 2012, 134, 878 .

(c) Wu, T.; Mu, X.; Liu, G. Angew. Chem., Int. Ed. 2011, 50, 12578 (d) Zhou, S. L.; Guo, L. N.; Wang, S.; Duan, X. H. Chem. Commun. 2014, 50, 3589.

[4] (a) Keith, J. A; Henry, P. M. Angew. Chem., Int. Ed. 2009, 48, 9038.

(b) McDonald, R. I.; Liu, G. S.; Stahl, S. S. Chem. Rev. 2011, 111, 2981.

[5] (a) Zhang, X.; You, S. L. Chem 2017, 3, 919.

(b) Lucet, D.; Le Gall, T.; Mioskowski, C. Angew. Chem., Int. Ed. 1998, 37, 2580. 
[6] Yuan, W.; Du, H.; Zhao, B.; Shi, Y. Org. Lett. 2007, 9, 2589.

[7] Du, H.; Zhao, B.; Yuan, W.; Shi, Y. Org. Lett. 2008, 10, 4231.

[8] Zhao, B.; Peng, X,; Cui, S.; Shi, Y. J. Am. Chem. Soc. 2010, 132, 11009.

[9] Zhao, B.; Peng, X.; Zhu, Y.; Ramirez, T. A.; Comwall, R. G.; Shi, Y. J. Am. Chem. Soc. 2011, 133, 20890

[10] Zhu, Y. G.; Shi, Y. Chem.-Eur. J. 2014, 20, 13901.

[11] Sequeira, F. C.; Turnpenny, B. W.; Chemler, S. R. Angew. Chem. 2010, 122, 6509 .

[12] Wang, Y. F.; Zhu, X.; Chiba, S. J. Am. Chem. Soc. 2012, 134, 3679

[13] Turnpenny, B. W.; Chemler, S. R. Chem. Sci. 2014, 5, 1786.

[14] Karyakarte, S. D.; Sequeira, F. C.; Zibreg, G. H.; Huang, G. Q.; Matthew, J. P.; Ferreira, M. M. M.; Chemler, S. R. Tetrahedron Lett. 2015, 56, 3686.

[15] Shen, K.; Wang, Q. Chem. Sci. 2015, 6, 4279.

[16] Khoder, Z. M.; Wong, C. E.; Chemler, S. R. ACS Catal. 2017, 7, 4775 .

[17] Weng, S. S.; Hsieh, K. Y.; Zeng, Z. J. Zhang, J. W. Tetrahedron Lett. 2017, 58, 670.

[18] Wang, F. L.; Dong, X. Y.; Lin, J. S.; Zeng, Y.; Jiao, G. Y.; Gu, Q. S.; Guo, X. Q.; Ma, C. L.; Liu, X. Y. Chem 2017, 3, 979.

[19] Chen, M. M.; Wang, L. J.; Ren, P. X.; Hou, X. Y.; Zhang, F.; Han, M. Nan.; Li, W. Org. Lett. 2018, 20, 510.

[20] Fu, S. M.; Yang, H. H.; Li, G. Q.; Deng, Y. F.; Jiang, H. F.; Zeng, W. Org. Lett. 2015, 17, 1018.

[21] Kinnel, R. B.; Gehrken, H. P.; Scheuer, P. J. J. Am. Chem. Soc. 1993, 115, 3376 .

[22] Li, S. Q.; Xiong, P.; Zhu, L.; Qian, X. Y.; Xu, H. C. Eur. J. Org. Chem. 2016, 20, 3449.

[23] Shen, K.; Wang, Q. Chem. Sci. 2017, 8, 8265.

[24] Shen, K.; Wang, Q. J. Am. Chem. Soc. 2017, 139, 13110.

[25] Pan, G. H.; Ouyang, X. H.; Hu, M.; Xie, Y. X.; Li, J. H. Adv. Synth. Catal. 2017, 15, 2564

[26] Zhang, Y, L.; Wang, M.; Cao, P.; Liao, J. Acta Chim. Sinica 2017, 75, 794 (in Chinese). (张涌灵，王敏，曹鹏，廖建，化学学报, 2017, 75, 794.)

[27] Gockel, S. N.; Buchanan, T. L.; Hull, K. L. J. Am. Chem. Soc. 2018, $140,58$.

[28] Zeng, W.; Chemler, S. R. J. Am. Chem. Soc. 2007, 129, 12948.

[29] Miao, L.; Haque, I.; Manzoni, M. R.; Tham, W. S.; Chemler, S. R. Org. Lett. 2010, 12, 4739

[30] Kaneko, K.; Yoshino, T.; Matsunaga, S.; Kanai, M. Org. Lett. 2013, 15,2502 .

[31] Wang, D. H.; Wu, L. Q.; Wang, F.; Wan, X. L.; Chen, P. H.; Lin, Z. Y.; Liu, G. S. J. Am. Chem. Soc. 2017, 139, 6811.

[32] Miller, Y.; Miao, L.; Hosseini, A. S.; Chemler, R. S. J. Am. Chem. Soc. 2012, 134, 12149.

[33] Zhou, S. L.; Guo, L. N.; Wang, H.; Duan, X. H. Chem.-Eur. J. 2013, 19, 12970 .

[34] Zhou, B.; Hou, W.; Yang, Y.; Feng, H.; Li, Y. Org. Lett. 2014, 167, 1322.

[35] Shi, L.; Wang, Y.; Yang, H.; Fu, H. Org. Biomol. Chem. 2014, 12, 4070 .

[36] Li, X.; Jian, X.; Zhang, P.; Gao, Y.; Wu, J.; Tang, G.; Zhao, Y. Synlett 2014, 25, 2009.

[37] Schlosser, M. Angew. Chem., Int. Ed. 2006, 45, 5432.

[38] Liang, Z.; Wang, F.; Chen, P.; Liu, G. S. Org. Lett. 2015, 17, 2438.

[39] Egami, H.; Shimizu, R.; Kawamura, S.; Sodeoka, M. Angew. Chem., Int. Ed. 2013, 52, 4000.

[40] Yang, F.; Klumphu, P.; Liang, Y. M.; Lipshutz, B. H. Chem. Commun. 2014, 50, 936.

[41] Egami, H.; Kawamura, S.; Miyazaki, A.; Sodeoka, M. Angew. Chem., Int. Ed. 2013, 52, 7841.

[42] Lin, J. S.; Liu, X. G.; Zhu, X. L.; Tan, B.; Liu, X. Y. J. Org. Chem. 2014, 79, 7084

[43] Lin, J. S.; Xiong, Y. P.; Ma, C. L.; Zhao, L. J.; Tan, B.; Liu, X. Y. Chem.-Eur. J. 2014, 20, 1332

[44] Lin, J. S.; Dong, X. Y.; Li, T. T.; Jiang, N. C.; Tan, B.; Liu, X. Y. J.
Am. Chem. Soc. 2016, 138, 9357.

[45] Shen, K.; Wang, Q. Org. Chem. Front. 2016, 3, 222

[46] Lin, J. S.; Wang, F. L.; Dong, X. Y.; He, W. W.; Yuan, Y.; Chen, S.; Liu, X. Y. Nat. Commun. 2017, 8, 14841.

[47] Zhu, R.; Buchwald, S. L. J. Am. Chem. Soc. 2012, 134, 12462.

[48] Zhu, R.; Buchwald, S. L. Angew. Chem., Int. Ed. 2013, 52, 12655.

[49] Jiang, X. Y.; Qing, F. L. Angew. Chem., Int. Ed. 2013, 52, 14177.

[50] Ye, J. H.; Song, L.; Zhou, W. J.; Ju, T.; Yin, Zh. B.; Yan, S. S.; Zhang, Z.; Li, J.; Yu, D. G. Angew. Chem., Int Ed. 2016, 34, 10022.

[51] Cheng, Y. F.; Dong, X. Y.; Gu, Q. S.; Yu, Z. L.; Liu, X. Y. Angew. Chem. 2017, 30, 9009 .

[52] Li, X. T.; Gu, Q. S.; Dong, X. Y.; Meng, X.; Liu, X. Y. Angew Chem., Int. Ed. 2018, 57, 7668 .

[53] Li, Z. L.; Li, X. H.; Wang, N.; Yang, N. Y.; Liu, X. Y. Angew. Chem., Int. Ed. 2016, 55, 15100

[54] Liu, Z. C.; Bai, Y. H.; Zhang, J.; Yu, Y. Q.; Tan, Z.; Zhu, G. G. Chem. Commun. 2017, 53, 6440.

[55] Fu, L.; Zhou, S.; Wan, X. L.; Chen, P. H.; Liu, G. S. J. Am. Chem. Soc. 2018, 140, 10965.

[56] (a) Brase, S.; Gil, C.; Knepper, K.; Zimmermann, V. Angew. Chem., Int. Ed. 2005, 44, 5188.

(b) Drivel, T. G. Org. Biomol. Chem. 2010, 8, 3831.

(c) Fumagalli, G.; Rabet, P. T. G.; Boyd, S.; Greaney, M. F. Angew. Chem., Int. Ed. 2015, 54, 11481.

[57] (a) Rong, J.; Han, J.; Dong, L.; Tan, Y.; Yang, H.; Feng, L.; Wang, Q. W.; Meng, R.; Zhao, J.; Wang, S. Q.; Chen. X. J. Am. Chem. Soc. 2014, 136, 17468

(b) Gramlich, P. M. E.; Wirges, C. T.; Manetto, A.; Carell, T. Angew. Chem., Int. Ed. 2008, 47, 8350.

[58] Yin, H.; Wang, T.; Jiao, N. Org. Lett. 2014, 16, 2302.

[59] Zhu, L.; Yu, H.; Xu, Z.; Jiang, X.; Lin, L.; Wang, R. Org. Lett. 2014, 16, 1562.

[60] Zhu, R.; Buchwald, S. L. J. Am. Chem. Soc. 2015, 137, 8069.

[61] Lu, M. Z.; Wang, C. Q.; Loh, T. P. Org. Lett. 2015, 17, 6110.

[62] Zhou, H.; Jian, W. J.; Qian, B.; Ye, C. Q.; Li, D. L.; Zhou, J.; Bao, H. L. Org. Lett. 2017, 19, 6120 .

[63] Bunescu, A.; Ha, T. M.; Wang, Q.; Zhu, J. P. Angew. Chem., Int. Ed. 2017, 56, 10555.

[64] Xu, L.; Mou, X. Q.; Chen, Z. M.; Wang, S. H. Chem. Commun. 2014, 50, 10676

[65] Wang, D. H.; Wang, F.; Chen, P. H.; Lin, Z. Y.; Liu, G. S. Angew. Chem., Int. Ed. 2017, 8, 2054.

[66] Qian, Bo.; Xiong, H. G.; Zhu, N. B.; Ye, C. Q.; Jian, W. J.; Bao, H. L. Tetrahedron Lett. 2016, 57, 3400.

[67] Hemric, B. N.; Shen, K.; Wang, Q. J. Am. Chem. Soc. 2016, 138, 5813.

[68] Ha, T. M.; Wang, Q.; Zhu, J. P. Chem. Commun. 2016, 52, 11100.

[69] Williamson, K. S.; Yoon, T. P. J. Am. Chem. Soc. 2010, 132, 4570.

[70] Liu, G. S.; Zhang, Y. Q.; Yuan, Y. A.; Xu, H. J. Am. Chem. Soc. 2013, 135, 3343

[71] Lu, D. F.; Zhu, C. L.; Jia, Z. X.; Xu, H. J. Am. Chem. Soc. 2014, 136, 13186.

[72] Yuan, Y. A.; Lu, D. F.; Chen, Y. R.; Xu, H. Angew. Chem. 2016, $128,544$.

[73] Qian, B.; Chen, S. W.; Wang, T.; Zhang, X. H.; Bao, H. L. J. Am. Chem. Soc. 2017, 139, 13076.

[74] Wang, X.; Buchwald, S. L. J. Am. Chem. Soc. 2011, 133, 19080.

[75] Olson, D. E.; Su, J. Y.; Roberts, D. A.; Bois, J. D. J. Am. Chem. Soc. 2014, 136, 13506.

[76] Piou, T.; Rovis, T. Nature 2015, 527, 86.

[77] Ciesielski, J.; Dequirez, G.; Retailleau, P.; Gandon, V.; Dauban, P. Chem.-Eur. J. 2016, 22, 9338.

[78] Fu, N. K.; Sauer, G. S.; Lin, S. J. Am. Chem. Soc. 2017, 139, 15548.

[79] Sun, H.; Cui, B.; Duan, L. L.; Li, Y. M. Org. Lett. 2017, 19, 1520.

[80] Singh, A. K.; Chawla, R.; Yadav, L. D. S. Tetrahedron Lett. 2014 55,4742 .

[81] Guo, S.; Cong, F.; Guo, R.; Wang, L.; Tang, P. P. Nat. Chem. 2017, 9,546 . 
[82] Fumagalli, G.; Boyd, S.; Greaney, M. F. Org. Lett. 2013, 15, 4398.

[83] Sipos, G.; Ou, A.; Skelton, B. W.; Falivene, L.; Cavallo, L.; Dorta, R. Chem.-Eur. J. 2016, 22, 6939

[84] Conway, J. H.; Rovis, T. J. Am. Chem. Soc. 2018, 140, 135.

[85] Martinez, C.; Wu, Y. C.; Weinstein, A. B.; Stahl, S. S.; Liu, G. S.; Muniz, K. J. Org. Chem. 2013, 78, 6309.

[86] Hata, K.; He, Z. H.; Daniliuc, C. G.; Itami, K.; Studer, A. Chem. Commun. 2014, 50, 463 .

[87] Ramella, V.; He, Z. H.; Daniliuc, C. G.; Studer, A. Org. Lett. 2015, 17, 664.

[88] Yu, F.; Chen, P. H.; Liu, G. S. Chem. Commun. 2016, 52, 11100.

[89] Zheng, J. H.; Chen, P.; Yuan, Y. F.; Cheng, J. J. J. Org. Chem. 2017, 82,5790 .

[90] Karnakanti, S.; Zang, Z. L.; Zhao, S.; Shao, P. L.; Hu, P.; He, Y. Chem. Commun. 2017, 53, 11205.

[91] Qi, X. X.; Chen, C. H.; Hou, Ch. Q.; Fu, L.; Chen, P. H.; Liu, G. S. J. Am. Chem. Soc. 2018, 140, 7415.

[92] (a) Cresswell, A. J.; Eey, S. T.-C.; Denmark, S. E. Nat. Chem. 2015, $7,146$.

(b) He, T. X.; Zeng, X. H. Chin. J. Org. Chem. 2017, 37, 798 (in Chinese).

(何天雄, 曾祥华, 有机化学, 2017, 37, 798.)

[93] Lin, J. S.; Yu, P.; Huang, L.; Zhang, P.; Tan, B.; Liu, X. Y. Angew. Chem., Int. Ed. 2015, 54, 7847.

[94] Yang, N. Y.; Li, Z. L.; Ye, L.; Tan, B.; Liu, X. Y. Chem. Commun.
2016, 52, 9052.

[95] Tsuji, N.; Kennemur, J. L.; Buyck, T.; Lee, S.; Prevost, S.; Kaib, P. S. J.; Bykov, D.; Fares, C.; List, B. Science 2018, 359, 1501.

[96] Lu, Q. Q.; Zhang, J.; Wei, F. L.; Qi, Y.; Wang, H. M.; Liu, Z. L.; Lei, A. W. Angew. Chem., Int. Ed. 2013, 52, 7156.

[97] Chen, H.; Kaga, A.; Chiba, S. Org. Lett. 2014, 16, 6136.

[98] Hong, K. B; Johnston, J. N. Org. Lett. 2014, 16, 3804.

[99] Danneman, M. W.; Hong, K. B.; Johnston, J. N. Org. Lett. 2015, 17, 2558.

[100] Xia, X. F.; Gu, Z.; Liu, W. T.; Wang, H. J.; Xia, Y. M.; Gao, H. Y.; Liu, X.; Liang, Y. M. J. Org. Chem. 2015, 80, 290.

[101] Fei, J.; Wang, Z.; Cai, Z. R.; Sun, H.; Cheng, X. Adv. Synth. Catal. 2015, 357, 4063.

[102] Zhou, S. F.; Pan, X. Q.; Zhou, Z. H.; Shoberu, A.; Zou, J. P. J. Org. Chem. 2015, 80, 3682.

[103] Huang, L.; Zheng, S. C.; Tan, B.; Liu, X. Y. Org. Lett. 2015, 17, 1589.

[104] Chumnanvej, N.; Katrun, P.; Pohmakotr, M.; Reutrakul, V.; Soorukram, D.; Kuhakarn, C. Chin. J. Chem. 2016, 34, 830.

[105] Zhang, Z. X.; Martinez, H.; Dolbier. W. R. J. Org. Chem. 2017, 82, 2589.

[106] Zhou, S. F.; Song, T.; Chen, H.; Liu, Z. L.; Shen, H. G.; Li, C. Z. Org. Lett. 2017, 19, 698.

[107] Muñiz, K.; Barreiro, L.; Romero, R. M.; Martínez, C. J. Am. Chem. Soc. 2017, 139, 4354.

(Cheng, F.) 